\title{
Geografía Económica del conocimiento de la aglomeración metropolitana de Bilbao
}

\author{
M Concepción TORRES ENJUTO \\ Departamento de Geografía, Prehistoria y Arqueología \\ Universidad del Pais Vasco \\ conchi.torres@ehu.es
}

Recibido: 30 de mayo de 2013

Enviado a evaluar: 5 de junio de 2013

Aceptado: 8 de julio de 2013

\section{RESUMEN}

La economía del conocimiento (EC) se ha erigido en un factor clave de competitividad regional y, por tanto, de diferenciación urbana en la Unión Europea, por lo que interesa conocer cómo está posicionada la aglomeración metropolitana de Bilbao (AMB), la principal del País Vasco. En las tres últimas décadas ha registrado una diversificación productiva, la consolidación de un sistema de innovación regional y el reajuste de la jerarquía urbana, que le ha valido un reconocimiento internacional. Resulta de interés conocer hasta qué punto es relevante la EC en volumen y estrategias de localización por su capacidad de transmisión de innovación al resto de los subsectores económicos y a los espacios urbanos conectados. Valorar hasta qué punto el territorio, entendido como una particular configuración socio-económica en una localización específica, importa de modo activo en la EC del AMB es el hilo conductor de este trabajo.

Palabras clave: Economía del conocimiento, localización, Bilbao, ciudad del conocimiento, metrópoli regional.

\section{Economic Geography of knowledge in the metropolitan area of Bilbao}

\begin{abstract}
Knowledge Economy has emerged as a key factor of regional competitiveness and therefore urban differentiation in the European Union, making it necessary to know how the metropolitan area of Bilbao is positioned, the main metropolis in the Basque Country. Over the last three decades Bilbao has seen a diversification of production, a consolidation of a regional innovation system, and a re-adjustment of the urban hierarchy which has earned it international recognition. It is interesting to know to what extent the knowledge economy is relevant in volume and localization strategies for its innovative transmission capacity to other economic subsectors and connected urban spaces. Assessing to what extent the territory, which is understood as a special socio-economic configuration at a specific location, actively matters in the economic knowledge of the metropolitan area of Bilbao is the driving force behind this paper.
\end{abstract}

Key words: Knowledge economy, location, Bilbao, city of knowledge, regional metropolis. 


\section{Géographie Economique de la connaissance dans l'agglomération métropolitaine de Bilbao}

\section{RÉSUMÉ}

L'économie de la connaissance (EC) s'est convertie en un facteur clé de la compétitivité régionale et, partant, en un facteur de différenciation urbaine au sein même de l'Union Européenne, c'est pourquoi il serait intéressant de nous interroger sur le positionnement de l'agglomération métropolitaine de Bilbao (AMB), en tant qu'elle constitue la principale agglomération métropolitaine du pays basque. Au cours de ses trois dernières décennies celle-ci a connu en effet une diversification productive, la consolidation d'un système d'innovation régional et le réajustement de sa hiérarchie urbaine, salué au plan international Aussi serait-il intéressant de savoir jusqu'à quel point l'EC peut-elle être déterminante, notamment en termes de volume et de stratégies de localisation, dans sa capacité à transmettre l'innovation au reste des sous-secteurs économiques et des espaces urbains connectés. Évaluer jusqu'à quel point le territoire, compris comme une configuration socioéconomique particulière ancrée au cour d'une localisation spécifique, pèse activement sur l'EC de L'AMB, constitue le fil conducteur de la présente analyse.

Mots clés: Économie de la connaissance, localisation, Bilbao, ville de la connaissance, métropole régionale.

\section{TERRITORIO Y ECONOMÍA DEL CONOCIMIENTO (EC)}

La interrelación entre transformaciones urbanas y económicas ocurridas en las áreas metropolitanas españolas ha sido analizada en períodos precedentes (Méndez y Caravaca, 1993; Méndez y Pascual edit. 2006). En la última década el avance del proceso de globalización y de la economía del conocimiento han intensificado los cambios registrados en el sistema urbano y la reorganización de la actividad económica en España. Efectivamente, "las grandes ciudades abandonan de forma progresiva la producción de bienes materiales en beneficio de una especialización en servicios, tanto destinados a la población como a las empresas. Por el contrario, en todas las actividades relacionadas con la producción de bienes materiales su importancia relativa aumenta al reducirse el tamaño de los núcleos" (Méndez edit. 2010, 164-165). Por todo ello resulta oportuno la realización de estudios sobre el tejido económico de las metrópolis regionales, que están entre las metrópolis de mayor tamaño (más de 1.000.000 habitantes en la ciudad central, como Madrid y Barcelona) y las ciudades intermedias (20.000-250.000). Nos referimos a las metrópolis regionales como aquellas cuya población del área metropolitana oscila entre 900.000 y 1.500.000 habitantes en 2009 según el Atlas estadístico de las áreas urbanas españolas. En dicho intervalo están Valencia, Sevilla, Málaga y Bilbao. Comprobar si la hipótesis de concentración de EC en áreas centrales de la metrópoli por las ventajas competitivas locales que ofrece (reducción de costes de transacción, entorno de negocios valorado, concentración de mano de obra cualificada, difusión de información y conocimiento tácito, infraestructuras específicas ...) y la dependencia de la EC de dichos recursos localizados que ha sido planteada en la región metropolitana de Madrid (Méndez y Tébar, 2011) tiene validez en la AMB es objeto del presente trabajo. 
En relación al cambio metropolitano y la EC el concepto de global-city-region ó región metropolitana global (Scott, 2002), planteado a partir de trabajos precedentes (Sassen, 1991; Castells, 1991), subraya la dimensión territorial y regional de estas enormes aglomeraciones urbanas. La región metropolitana está referida al ámbito territorial integrado por una metrópoli principal de carácter internacional y el conjunto de ciudades y enclaves urbanos de menor tamaño que están vinculados funcionalmente en su entorno por movimientos de residencia-trabajo, desplazamientos laborales, viajes diarios ó semanales vinculados a la educación, la sanidad, el ocio y el comercio. El carácter internacional de la metrópoli principal se debe a la concentración de órganos decisorios y organizativos de las empresas multinacionales y nacionales, de sedes financieras, de servicios avanzados, de medios de comunicación y de conexiones de transportes. Esta concentración de funciones económicas y de representación a nivel internacional, estrechamente vinculadas a la EC, genera una intensa conectividad con otras urbes de similar y menor perfil, articulándose una red mundial de metrópolis que sustentan las actuales condiciones de globalización económica (Taylor, 2011). A nivel intrametropolitano, la densidad de flujos de mercancías, información, conocimiento y personas ya no son solamente entre el centro y la periferia, sino que las interrelaciones entre las ciudades y núcleos entre las diferentes coronas metropolitanas cobran intensidad. El protagonismo funcional de las periferias metropolitanas, no es sólo debido a las áreas residenciales, industriales y logísticas, sino sobre todo por la consolidación de los clusters de EC y sedes principales de empresas relevantes, localizados en determinados subcentros que articulan el policentrismo de estas complejas regiones metropolitanas (Hall y Pain, 2005).

De menor tamaño que las regiones metropolitanas y conectadas a ese primer rango urbano están las metrópolis regionales. Inmersas en el proceso de globalización económica y urbana, en el comienzo del siglo veintiuno se han hecho aún más evidentes las amenazas y oportunidades que trae consigo: desindustrialización en determinadas zonas de la metrópoli y la aparición de actividades vinculadas a la EC en otras zonas. La reorganización espacial y económica de la metrópoli regional (tabla 1) supone una redistribución de actividades y tareas, que materializa la respuesta de la metrópoli a los procesos de globalización y competencia entre metrópolis (Méndez, 2007). A nivel intrametropolitano, el precio del suelo y la accesibilidad son los factores genéricos que influyen en la localización de las actividades de la EC, ubicadas en las áreas más accesibles y valoradas desde el punto de vista socioeconómico y paisajístico. Paralelamente, la progresiva presión a la expulsión de la actividad industrial de las áreas más céntricas y primera corona metropolitana es incentivada por expectativas de cambio de uso del suelo.

La consolidación de ventajas competitivas locales en torno al conocimiento es lo que ha apuntalado a las metrópolis regionales (clusters de innovación, calidad de infraestructuras y recursos humanos, concentración de inversiones públicas, economías de aglomeración...). Participan de la EC en un volumen modesto respecto al total del país y de una limitada proporción de funciones, actividades y servicios, que no sólo afectan al ámbito regional, sino que también contribuyen a determinadas deci- 
siones y fabricaciones de carácter internacional, por seguir manteniendo ubicados centros de decisión, establecimientos productivos e inversores locales de cierta entidad en la región y a nivel global. La participación de empresas regionales en dichas redes de producción global (global production networks) asegura que la interacción entre la globalización económica y el cambio regional sea más dinámica. El encaje estratégico entre lo local y lo global es clave para entender el desarrollo regional en la era de la globalización (Yeung, 2009). El encaje estratégico es definido como un proceso dinámico a través del cual los agentes locales (empresas e instituciones políticas, sociales y económicas) coordinan los intereses entre los agentes locales y sus homólogos en la economía global. Este encaje estratégico es decisivo en el papel desempeñado por la metrópoli en lo relativo a la tecnología, el conocimiento y las finanzas en el contexto internacional. Una aproximación al lugar que ocupan a nivel mundial las metrópolis ha sido investigado en base a la localización de la categoría de los establecimientos (sede, oficina de ámbito regional a nivel global, oficina de tamaño grande etc.) de las empresas de servicios avanzados (banca, seguros e intermediación financiera, contabilidad, publicidad, asesoría jurídica, consultoría y medios de comunicación) (Taylor, 2011).

El estudio de la interrelación entre la región metropolitana y la economía del conocimiento en España ha sido debatido por Méndez y Sánchez-Moral (2011), que proponen un marco teórico en el que distinguen factores, componentes y efectos en la construcción de las ciudades basadas en el conocimiento. Los factores vinculados al territorio que subrayan son las economías de aglomeración, las instituciones y agentes locales, la accesibilidad y los procesos de difusión, la gobernanza del conocimiento. Los componentes que distinguen de las áreas metropolitanas basadas en el conocimiento son la acumulación de recursos específicos para la generación de conocimiento, y que está focalizado en el capital humano; una estructura económica en la que los sectores y las empresas intensivos en conocimiento ocupan una posición preferente; un sistema de innovación regional, basado en las redes de agentes locales y regionales que está apoyado en la infraestructura digital para facilitar el intercambio de información y conocimiento; los resultados tangibles de la innovación en el ámbito económico y urbano. Un breve comentario sobre cada uno de los elementos diferenciadores de la metrópoli del conocimiento es anotado a continuación.

En relación al capital humano hay que destacar el largo período de formación que exige la mano de obra cualificada y su preferencia residencial por ciudades que ofrecen una alta calidad de vida. Su papel estratégico en la generación de innovación y conocimiento ha sido subrayada con los términos talento y clase creativa (Florida, 2005). En la metrópoli del conocimiento el número y proporción de titulados universitarios es más elevado por las demandas laborales requeridas en la EC y resto de actividades productivas. En un reciente informe señalan que las empresas están reteniendo a los trabajadores más formados, lo cual está contribuyendo a la mejora de la productividad de las empresas españolas y que el País Vasco, una de las regiones más desarrolladas tecnológicamente, cuenta con mayor capacidad para atraer capital humano (Pérez García dir., 2012). 
Tabla 1. Reorganización espacial y económica de metrópoli regional.

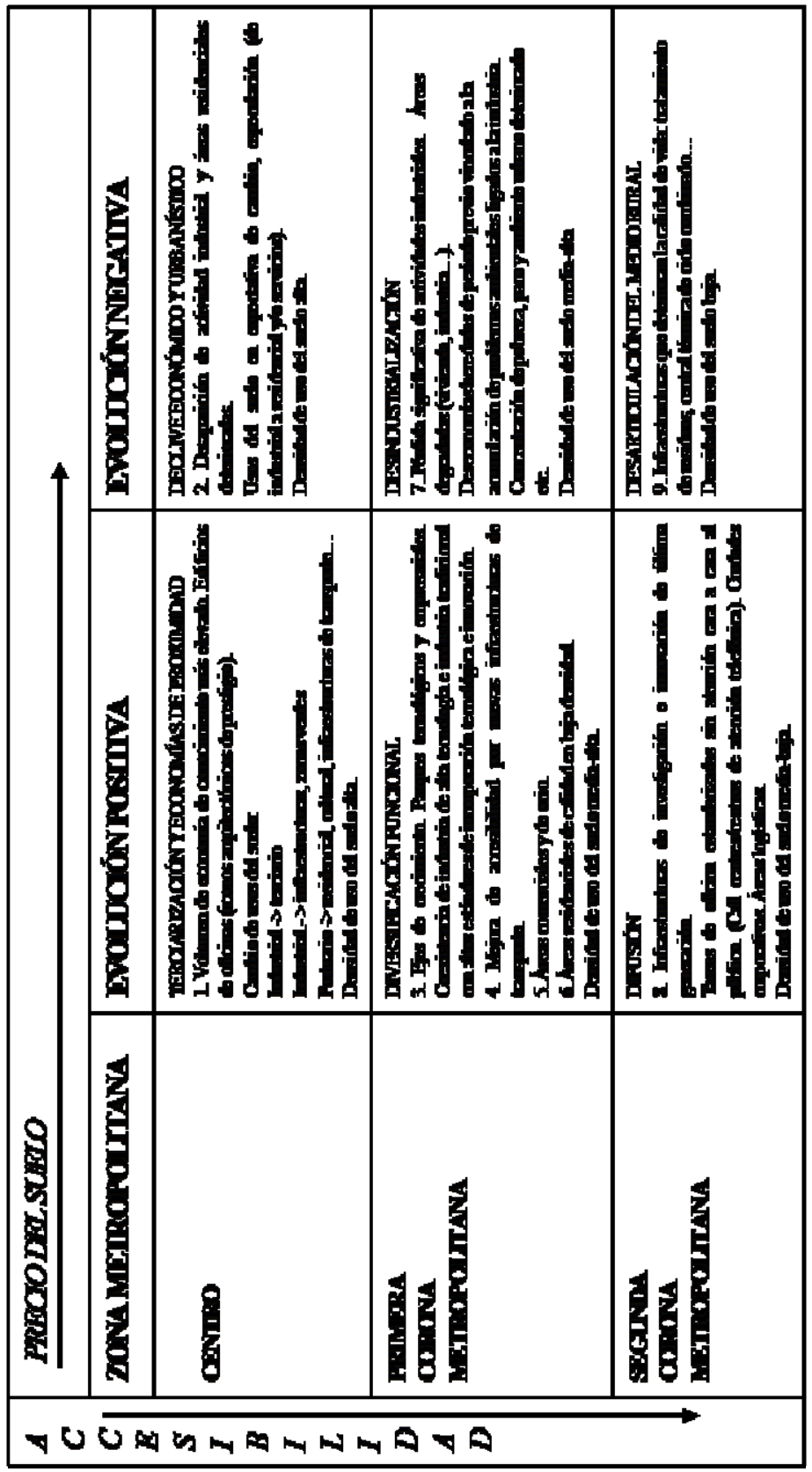

Fuente: Elaboración propia 
Sobre la estructura económica desde la teoría del ciclo del producto hay que recordar que la especialización de territorios en actividades que experimentan un alto crecimiento en un período dado favorecerá un mejor comportamiento económico que aquellos territorios que alojan actividades en declive. Temática analizada en las regiones españolas en diferentes períodos económicos (Pérez, Goerlich y Mas 1996; Bosque Maurel y Méndez edit. 1995). En este sentido el País Vasco resulta de gran interés por los cambios acontecidos en el sistema productivo en la primera gran transformación económica (1980-1998), que significó la integración de tecnología e innovación a sectores existentes y la diversificación del tejido productivo (Alberdi, 2010). La segunda gran transformación económica tiene por objetivo convertir al País Vasco en una región líder en conocimiento, donde los subsectores intensivos en tecnología, conocimiento e innovación tengan una mayor participación en el empleo y en la generación de VAB regional (Gobierno Vasco, 2010). Dichos subsectores asociados a la EC producen, transfieren y aplican el conocimiento de modo más intenso, lo cual induce a generar tasas de innovación más altas y nuevas especializaciones. El uso de factores basados en el conocimiento está nucleado en torno a cuatro tipos de clusters de innovación (tabla 2).

Tabla 2. Clusters de innovación en la EC (adaptado a códigos CNAE-2009)

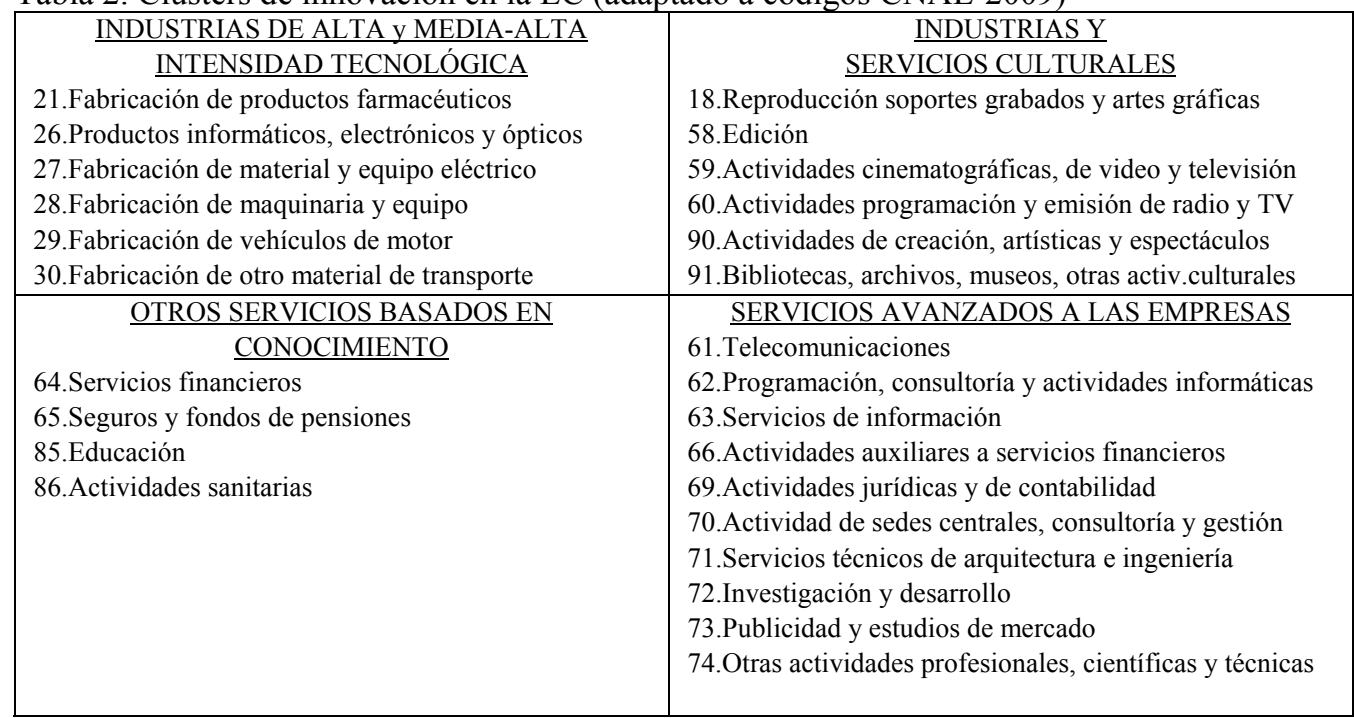

Fuente: Adaptado de Méndez y Tébar 2011.

El sistema de innovación regional vertebra los enlaces entre generación de conocimiento, aprendizaje, procesos de innovación y desarrollo económico. Las regiones y ciudades que generan una alta tasa de producción y aplicación de conocimiento en el tejido empresarial y la gestión pública tendrán un recurso competitivo fundamental a su disposición. Pero no sólo las redes locales permiten explicar la generación de redes de externalidades y la asimilación de procesos de innovación a través de la creación 
de comunidades basadas en el conocimiento. La creciente importancia de procesos globales en las dinámicas urbanas ha de ser considerada. La intensidad y el equilibrio de las relaciones establecidas entre los componentes del sistema de innovación local y el exterior (transferencias de capital y conocimiento, participación en proyectos, intercambios de profesionales) pueden proporcionar indicadores relevantes (Méndez, 2000). El sistema de innovación regional del País Vasco ha sido ampliamente investigado (Navarro, 2010; OCDE, 2011), coincidiendo en que hay margen de mejora en la interconexión entre los diferentes agentes, en la capitalización económica de la inversión en $\mathrm{I}+\mathrm{D}+\mathrm{i}$ y en el impulso a la investigación científica en áreas relevantes del tejido económico de la región.

Sobre los resultados tangibles de la innovación en el ámbito económico y urbano hay que señalar que mantener a una ciudad posicionada en la EC requiere un constante esfuerzo en inversión de recursos financieros para enraizar la investigación, el desarrollo tecnológico y las transferencias de conocimiento, tanto en el ámbito privado como en el público. Los indicadores más habituales son número de patentes y modelos de utilidad registrados por las empresas, número de publicaciones científicas, certificados de calidad de las empresas y organismos públicos, aumento de cuotas de exportación. En lo relativo a los logros de la innovación en el ámbito urbano los indicadores referenciados son la participación en redes de ciudades a escala nacional, europea y global, una mejor inserción en circuitos internacionales urbanos de méritos (títulos de la ciudad, premios...). Asimismo, una gestión pública transparente y eficaz que implemente soluciones originales a los problemas urbanos de las desigualdades espaciales es un activo a destacar. En definitiva, un estilo de gestión pública que introduce la creatividad como valor estratégico para abordar los retos del futuro del territorio (Clark, Huxley y Mountford, 2010).

Por otra parte, Hutton (2007) destaca una serie de componentes intangibles de la ciudad del conocimiento como liderazgo, diferenciación y colaboración, que están interrelacionados con los tangibles. Las ciudades que apuestan por el conocimiento precisan de un liderazgo capaz de aunar a los agentes clave (instituciones locales, gobierno regional, organizaciones empresariales, universidad ...) y de generar un ambiente de objetivo compartido para superar las deficiencias detectadas en la ciudad. La diferenciación de la ciudad apoyada en sus fortalezas (conocimiento original, capacidades productivas...) permite reforzar las ventajas comparativas de la ciudad, logrando una ciudad del conocimiento que se distingue de otras y que ofrece aspectos complementarios a otras urbes próximas. La colaboración con otras ciudades permite aunar fortalezas y afrontar conjuntamente desafíos de la EC. Esa colaboración ha de estar apoyada en acuerdos realistas y genuinos desde el reconocimiento de la posición de cada ciudad en el sistema urbano.

En la UE la aspiración a una mayor relevancia de la EC desde el punto de vista económico y social fue aprobada hace tiempo (Estrategia de Lisboa, Consejo Europeo de 2000) y continúa siendo un objetivo pendiente de lograr (Comisión Europea, 2010). En ese ámbito europeo ha sido realizada una investigación empírica sobre la $\mathrm{EC}$ en las regiones europeas. Han sido identificados como determinantes claves en 
una economía regional basada en el conocimiento (Wintjes-Hollanders, 2010) la accesibilidad al conocimiento, la asimilación y la rentabilización. Estas tres dimensiones del conocimiento consisten en la interpretación del sistema de innovación regional comentado previamente. La accesibilidad al conocimiento implica acceder al conocimiento existente y generación de nuevo saber, la absorción significa aprendizaje, los procesos de innovación y desarrollo económico son sinónimos de la rentabilización del conocimiento. Estas tres dimensiones del conocimiento implican un evidente componente territorial debido a la distribución espacial no homogénea del conocimiento. Las metrópolis y las regiones más prósperas disfrutan de capacidad para generar nuevo conocimiento, mayor accesibilidad al existente, capacidad para asimilarlo y traducirlo en iniciativas empresariales. Las ciudades de menor tamaño y regiones periféricas han de afrontar una accesibilidad al mismo ya limitada. Las metrópolis regionales pueden tener opciones en la explotación de aplicaciones específicas del nuevo conocimiento, enlazándolo con las cadenas de valor globales localizadas en su región (Lagendijk, 2011), así como en la generación de nuevo conocimiento en relación a especializaciones sectoriales precedentes y vinculado a nuevas actividades.

Teniendo en cuenta esas tres dimensiones del conocimiento seleccionaron varios indicadores (servicios intensivos en conocimiento, industria de alta tecnología, trabajadores creativos, tasa de actividad, I+D en empresas, I+D en centros públicos, productividad) para elaborar el mapa del conocimiento de las regiones de la UE. Numerosos indicadores coinciden con los analizados en los componentes de la ciudad basada en el conocimiento que proponen Méndez y Sánchez-Moral (2011) como consecuencia del consenso conceptual sobre la relevancia de la EC en las regiones y en el contexto internacional. En función de esos indicadores (Wintjes-Hollanders, 2010) han distinguido varios tipos de EC regional. La primera categoría serían las regiones metropolitanas de servicios intensivos en conocimiento y que suelen coincidir con la capital del país. La segunda categoría serían las regiones absorbiendo conocimiento y es en la que aparece el País Vasco. En el País Vasco el debate sobre la EC ha sido planteado a escala regional con el concepto de territorio inteligente (Esteban, Ugalde, Rodríguez y Altuzarra 2008), que aúna territorio y sistema de innovación regional. El modelo conceptual (Fernández-Macho y González, 2009, 55) propuesto sobre el territorio inteligente es el que está apoyado en el subsistema económico (industrias creativas, talento, innovación y emprendizaje, internalización o glocal), físico y construido (gestión medioambiental, urbanismo y territorio, eficiencia energética, movilidad) y social (gobernanza, cohesión social, diversidad e identidad). Este modelo ha sido aplicado a 231 regiones NUTS2 de la UE para las que existían un conjunto suficiente de indicadores de economía creativa en la base Regio de Eurostat. La obtención de un índice global que tiene en cuenta los indicadores de los tres subsistemas citados sitúa al País Vasco en 85 (siendo el mejor 1 y el peor 231), Madrid aparece con una valoración de 74 y las tres regiones europeas mejor posicionadas son Berkshire-Buckinghamshire (Reino Unido), Estocolmo (Suecia) y EteläSuomi (Finlandia). Un buen número de indicadores utilizados en este estudio también coinciden con los seleccionados en los trabajos previamente citados. 
Sin embargo, debido al carácter metropolitano de la EC resulta oportuno abordarlo a esa escala. Existen trabajos precedentes sobre la EC para las dos principales metrópolis españolas, Barcelona (Boix, 2006; Muñiz y García-López, 2009; Sánchez Pérez, J.E. coord. 2009) y Madrid (Méndez y Tébar, 2011), que serían las únicas metrópolis que pueden catalogarse como regiones metropolitanas. Aunque algunos autores han propuesto entender el País Vasco en su conjunto como un cluster de conocimiento (Arboníes y Moso, 2002), o una ciudad global policéntrica (Meijers et al., 2008) debido a las crecientes interacciones entre buena parte de sus empresas y territorios, son también evidentes los contrastes que aún se mantienen entre las ciudades que componen su sistema urbano y el liderazgo funcional que ejercen sus principales aglomeraciones.

En este artículo nos proponemos analizar la geografía económica del conocimiento en la aglomeración metropolitana de Bilbao y reflexionar sobre si reúne los requisitos diferenciadores de las metrópolis que ocupan una posición destacada en el conocimiento. Es decir, si es una ciudad del conocimiento en relación a los componentes que definen estas ciudades. La hipótesis a contrastar es si la EC requiere de una serie de factores específicos y localizados en determinadas áreas de la metrópoli para el desarrollo de esos cuatro subconjuntos de actividades identificados con la EC. La cuestión es comprobar si la EC precisa de una acumulación de capital humano, productivo, infraestructural, institucional y relacional. Averiguar si la proximidad e interrelación entre los diferentes factores de localización en entornos urbanos valorados y accesibles permiten el intercambio de conocimiento tácito, un ambiente de negocios estimulante para emprender nuevos proyectos y la agilidad institucional que exige la actual fase de globalización. $\mathrm{O}$ si por el contrario, la EC disfruta de una flexibilidad locacional apoyada en la mejora de los transportes y telecomunicaciones. Y por tanto, el territorio ha dejado de ser un obstáculo para el movimiento de personas, mercancías, información y conocimiento, lo que apuntaría hacia una redistribución de la actividad económica más difusa y equilibrada en el territorio.

\section{ACTIVIDADES Y EMPLEOS EN ECONOMÍA DEL CONOCIMIENTO EN LA AGLOMERACIÓN METROPOLITANA DE BILBAO}

La aglomeración metropolitana de Bilbao (AMB) ha experimentado una notable evolución en límites y estructura espacial, al igual que otras áreas metropolitanas del entorno europeo, en consonancia con las transformaciones económicas, sociales y territoriales ocurridas. Fue vislumbrada por Bastida (1923) y reconocida en 1964 por la Corporación Administrativa Gran Bilbao (incluía 18 municipios) para la ejecución del Plan de Ordenación Urbanística y Comarcal de Bilbao y su zona de Influencia. En 1980 es establecida la clasificación estadística comarcal del País Vasco (www.eustat.es) y que denomina Gran Bilbao (26 municipios) al conjunto de municipios que consideran más vinculados a la capital vizcaína. En 1997 las Directrices de Ordenación del Territorio (DOT) definen el Plan Territorial Parcial (PTP) del área funcional de Bilbao Metropolitano (35 municipios). En la década de 2000 el "Atlas 
Estadístico de las Áreas Urbanas Españolas" (Ministerio de Vivienda, 2007) acota para el caso de Bilbao el mismo conjunto de municipios que el PTP de Bilbao Metropolitano. Desde el ámbito de la geografía urbana (Feria Toribio, 2010) han delimitado las áreas urbanas de España atendiendo al criterio de movilidad residenciatrabajo. Así, el área urbana de Bilbao engloba 93 municipios, siendo algunos de los municipios seleccionados de provincias limítrofes dentro del País Vasco (como el caso de Álava) y fuera de la comunidad autónoma (municipios de Cantabria).

La valoración de las clasificaciones existentes no resultó satisfactoria de acuerdo a la realidad metropolitana y económica actual por lo que procedimos a una delimitación más ajustada a la evolución socio-económica en la década de 2000. En un trabajo anterior (Esteban y Torres, 2006) sobre la industria en el AMB utilizamos una delimitación que incluía los municipios del PTP de Bilbao Metropolitano y Duranguesado, precedente de la que proponemos. En este artículo la definición del AMB está apoyada en base a la evolución registrada de 2000 a 2009 en densidad de población y empleo, dinamismo demográfico y laboral, intensidad de flujos de personas por diferentes motivos (empleo, educación, sanidad, compras, ocio) en la isocrona de 30 minutos en automóvil con origen ó destino en Bilbao, sinergias estadísticas y límites administrativos de Vizcaya. Teniendo en cuenta esos criterios y previo análisis de los datos anteriores entendemos que la AMB incluye las comarcas (del Eustat) de Gran Bilbao, Duranguesado y Plentzia-Mungia (mapa 1). La comarca central ó primera corona es Gran Bilbao y en la aureola inmediata está la segunda corona ó ejes laterales que corresponden a Duranguesado y Plentzia-Mungia. Esta actualización de la AMB es más acorde a la estructura territorial vigente de áreas residenciales, laborales, principales ejes de transporte, flujos de personas, mercancías e información de comienzos del siglo XXI. Es una delimitación que comprende el $90 \%$ de la población de Vizcaya en 2011 y el 40,6\% de la superficie de dicha provincia. Datos elocuentes que manifiestan la progresión del fenómeno metropolitano por buena parte de la provincia vizcaína. La identificación entre la capital (Bilbao) y su provincia ó territorio histórico (Vizcaya) queda avalada por la colaboración interinstitucional entre el Ayuntamiento de Bilbao y la Diputación de Vizcaya. Además, la realidad metropolitana del AMB no puede disociarse de su comunidad autónoma, País Vasco, como veremos a continuación. 
Mapa 1. Municipios de Vizcaya y delimitación de la AMB

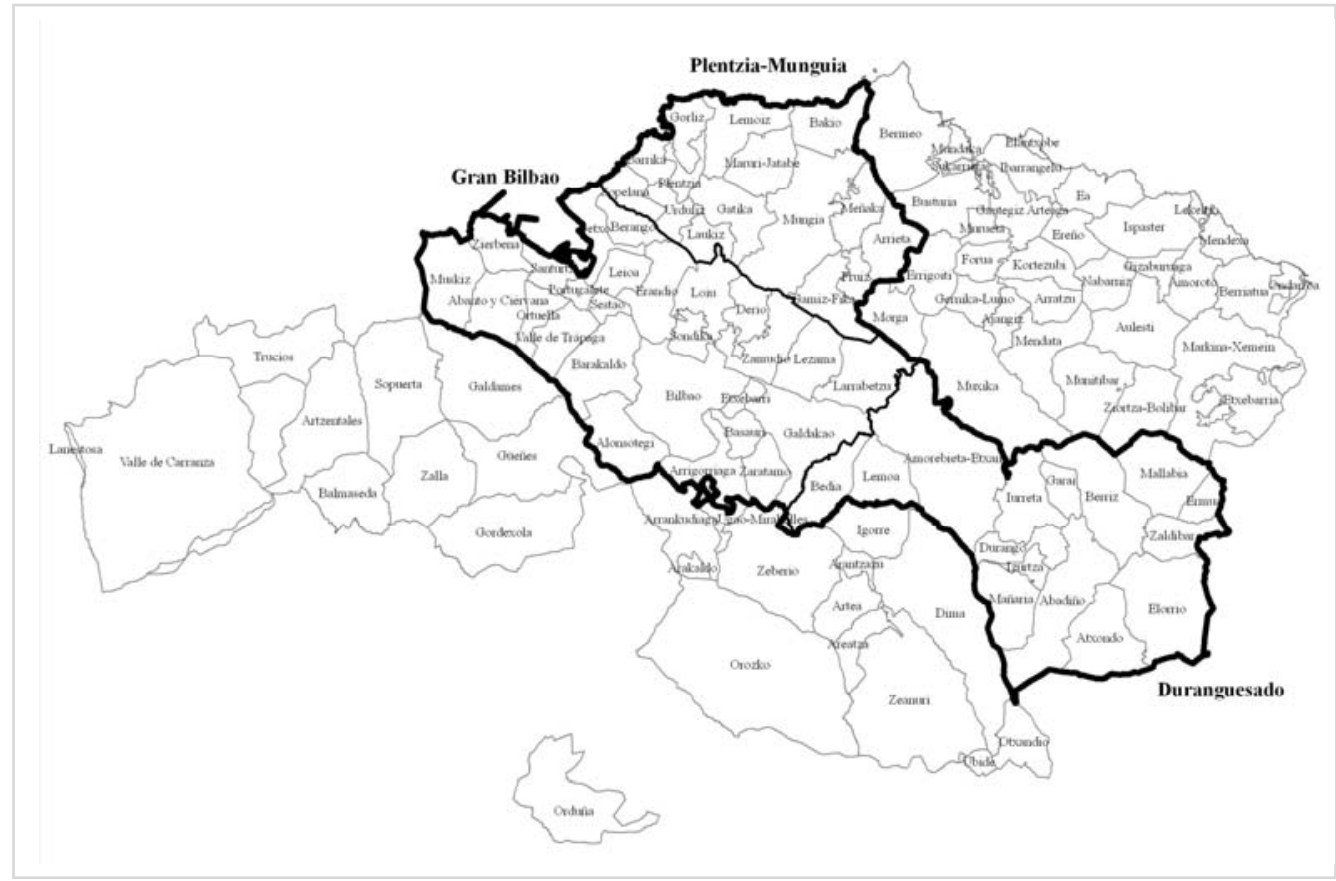

Fuente: Eustat y elaboración propia.

\subsection{PRIMACÍA JERÁRQUICA EN LA RED URBANA Y EN LA ECONOMÍA DEL PAÍS VASCO}

Las escalas espaciales inmediatas en las que está incardinada la AMB (provincia/Territorio Histórico ${ }^{1}$ y País Vasco) constituyen una referencia ineludible, que abordaremos a continuación, puesto que la articulación entre el tejido económico y la red urbana ha de integrarse en dichas escalas para comprender la economía del conocimiento (EC) en el ámbito metropolitano objeto de análisis. La distribución de la actividad económica en el País Vasco se caracteriza por un reparto desigual del empleo entre sus tres Territorios Históricos (TH) (tabla 3). En 2009 Vizcaya supone el $50 \%$ del empleo total en el País Vasco y esta participación predominante se repite

\footnotetext{
${ }^{1}$ La unidad espacial de provincia y Territorio Histórico $(\mathrm{TH})$ es equivalente desde el punto de vista de la extensión territorial. Sin embargo, los Territorios Históricos de Álava, Guipúzcoa y Vizcaya son así denominados por la capacidad fiscal de cada una de sus Diputaciones.
} 
en cualquier sector económico. Guipúzcoa ocupa el segundo lugar respecto al volumen total de empleo en la comunidad autónoma (33\%) y Álava supone una aportación más moderada (17\%). El perfil sectorial de cada TH también queda individualizado. En Vizcaya en 2009 es donde los servicios concentran un porcentaje más elevado (71,9\%), seguido de Guipúzcoa $(65,7 \%)$ y Álava (62,6\%). La distribución no homogénea de actividades económicas entre los diferentes $\mathrm{TH}$ y la configuración sectorial diferenciada están relacionadas con diversos factores: la antigüedad del proceso de industrialización, las economías de aglomeración de cada capital, el diferente comportamiento en períodos de crecimiento económico, el distinto ritmo en el proceso de terciarización, los niveles de accesibilidad, la disponibilidad de suelo urbanizable, la diversidad y capacidad de las infraestructuras, la inserción en la economía global y la red urbana europea (Torres, 1998).

Tabla 3. Distribución del empleo por sectores y T.H. en 2009

\begin{tabular}{|l|c|c|c|c|c|}
\cline { 2 - 6 } \multicolumn{1}{c|}{} & Agricultura & Industria & Construcción & Servicios & TOTAL \\
\hline ÁLAVA & 4.763 & 40.954 & 10.992 & 94.779 & 151.488 \\
\hline GUIPUZCOA & 3.153 & 77.330 & 24.418 & 200.904 & 305.805 \\
\hline VIZCAYA & 4.939 & 82.938 & 41.469 & 330.421 & 459.767 \\
\hline CAPV & 12.855 & 201.222 & 76.879 & 626.104 & 917.060 \\
\hline
\end{tabular}

Fuente: Tesorería General de la Seguridad Social 2009 y elaboración propia.

Estos factores de diferente índole han configurado un modelo territorial específico en cada TH y que en conjunto han dado como resultado en el País Vasco una red urbana muy consolidada. Según Ruiz y Galdós $(2008$, 153) Bilbao sólo ostenta la primacía jerárquica en la actividad económica y centralidad, pero no en las funciones administrativas, culturales, de servicios y turísticas. Juaristi (2009) sostiene que en el período 1981-2006 no ha habido una transformación sustancial del modelo de sistema urbano y que en dicho sistema Bilbao mantiene el liderazgo, aunque la renovación metropolitana está todavía por consolidarse en el ámbito económico. Este liderazgo de Bilbao ha intentado ser neutralizado con el discurso de Euskal Hiria/Ciudad Vasca (Gobierno Vasco y Fundación Metrópoli, 2002), que asimila todo el País Vasco a una gran metrópoli, soslayando las diferencias entre las tres urbes vascas para transmitir un supuesto mensaje de unidad territorial.

La red urbana del País Vasco está cimentada en dos áreas metropolitanas, Bilbao y San Sebastián (873.742 y 322.726 habitantes en 2011 respectivamente en las comarcas de Gran Bilbao y Donostia-San Sebastián según la comarcalización del Eustat) y una ciudad intermedia, Vitoria (cuya comarca, Llanada Alavesa, aloja a 254.761 habitantes en dicho año). Las dos áreas metropolitanas confluyen en Eibar, a igual relación de distancia-tiempo de ambas capitales, conformando un continuo urbano entre Bilbao y San Sebastián (que sigue el eje de la AP-8), al que está vinculado la capital alavesa por medio de la autopista Urbina-Málzaga, que conecta Vitoria con 
Eibar. En dicha red urbana la AMB desempeña un papel predominante por población, actividad económica, infraestructuras, amenidades y grado de internacionalización de Bilbao. La AMB es conocida a nivel mundial por el museo Guggenheim, pero también por haber pasado de ser una metrópoli industrial a una de servicios (Esteban y Torres, 2006). La profunda crisis industrial (1978-1984) obligó a una reorganización de los pilares económicos, pasando de apoyarse excesivamente en la industria pesada (siderurgia, transformados metálicos, construcción naval) (Torres, 1995) a destacar en sectores basados en la tecnología y el conocimiento en la actualidad. Tras más de tres décadas de apuesta por la innovación en el tejido empresarial existente, apoyo a sectores de alto contenido tecnológico, inversión en infraestructuras y recualificación urbana el AMB ha emergido como referente de transformación urbana y económica a nivel internacional (Committee of Digital and Knowledge-based cities, 2012). El predominio de Vizcaya en el tejido productivo y de Bilbao en la red urbana del País Vasco va a plasmarse igualmente en la economía del conocimiento, al estar basada en buena parte en subsectores de servicios como veremos en el siguiente epígrafe.

\subsection{VOLUMEN DE LA ECONOMÍA DEL CONOCIMIENTO EN 2009 Y LOCALIZACIÓN}

Como se apuntaba en el epígrafe 1 el País Vasco aspira a un liderazgo tecnológico, científico y empresarial, que a su vez redunde en la productividad, la riqueza y el bienestar de la población. Las instituciones vascas (Gobierno Vasco y Diputaciones) aspiran a posicionar al País Vasco como una de las regiones de mayor atractivo internacional para el talento. En el informe de la OCDE (2011: 44) sobre la innovación en el País Vasco señalan que dicha región "está intentando pasar de un modelo de innovación incremental y de reducción de costes a un modelo que sea más intensivo en conocimiento". Es el Plan de Ciencia, Tecnología e Innovación (PCTI) 20072010 del Gobierno Vasco el que plasma el objetivo de promover dicha transformación (OCDE 2011: 47). Pero, ¿cuál es la situación de la EC en lo relativo volumen, estructura y localización en 2009?. Esta investigación dispone de datos inéditos (Tesorería de la Seguridad Social de 2009) que permiten combinar desagregación de empleo por subsector a nivel de municipio. Esto constituye una auténtica novedad, ya que ofrece una cuantificación apoyada en evidencia de la dimensión de la EC a nivel territorial con desagregación municipal y aporta bases estadísticas fiables al debate sobre la EC. Otras publicaciones (Bilbao Lan Ekintza, 2009) sólo ofrecen datos del número de establecimientos, lo que dificulta conocer la importancia socio-económica de cada sector. De modo que realizar una valoración sectorial y territorial del fenómeno, que complete otras perspectivas existentes (Ekonomiaz $n^{\circ} 45$ y n $^{\circ} 78$ ) es un objetivo esencial. Frente a la visión plana y uniforme que suele transmitirse desde las instituciones haciendo sólo referencia a los datos del País Vasco y soslayando las diferencias entre $\mathrm{TH}$, comarcas y ciudades, aquí quisiéramos situar en primera línea la cuestión territorial, puesto que la especificidad económica de cada comarca requiere 
políticas diferenciadas para promover la competitividad (Navarro, Aranguren y Magro, 2012) y la EC resulta estratégica en el desarrollo territorial.

Los siguientes datos nos aproximan a un somero análisis. El 49,7\% del total de empleos en EC del País Vasco (tabla 4) está localizado en Vizcaya y supone ya el $28,6 \%$ respecto al total del tejido productivo vizcaíno. La participación de Guipúzcoa ${ }^{2}$ y Álava en la EC de la región (35\% y 15\% respectivamente) es prácticamente proporcional a su porcentaje en el conjunto de los sectores. De modo que se parte de un reparto territorial desigual de la actividad económica pero dentro de esa diferencia inicial la participación es coherente con la entidad de cada $\mathrm{TH}$, lo que proporciona más consistencia a la red urbana del País Vasco. Veamos qué ocurre al descender en la escala geográfica y llegar al nivel metropolitano en Vizcaya.

Tabla 4. Volumen de empresas y afiliados en economía del conocimiento (EC) en País Vasco por TH en 2009.

\begin{tabular}{|c|c|c|c|c|c|c|c|c|c|}
\hline $\begin{array}{l}\text { Unidades } \\
\text { Territoriales }\end{array}$ & 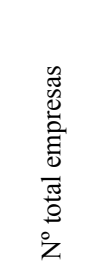 & $a^{\circ}$ & 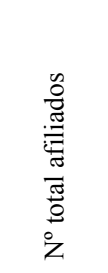 & $0^{\circ}$ & 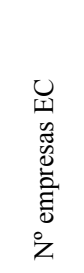 & $\partial^{\circ}$ & 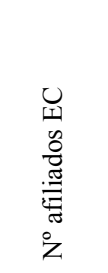 & 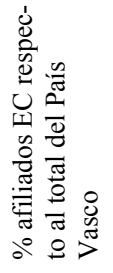 & 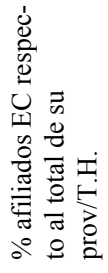 \\
\hline Vizcaya & 40.858 & 50,69 & 459.767 & 50,53 & 7.425 & 53,07 & 131.511 & 49,70 & 28,6 \\
\hline Guipúzcoa & 27.454 & 34,06 & 300.007 & 32,97 & 4.516 & 32,28 & 92.955 & 35,13 & 31,0 \\
\hline Álava & 12.287 & 15,24 & 150.140 & 16,50 & 2.051 & 14,66 & 40.163 & 15,18 & 26,8 \\
\hline $\begin{array}{l}\text { Total País } \\
\text { Vasco }\end{array}$ & 80.599 & 100 & 909.914 & 100 & 13.992 & 100 & 264.629 & 100 & 29,1 \\
\hline
\end{tabular}

Fuente: Tesorería General de la Seguridad Social 2009 y elaboración propia.

La aglomeración metropolitana de Bilbao (AMB) en 2009 (tabla 5) supone el $46,4 \%$ del empleo total del País Vasco y el $92,6 \%$ del total del empleo en Vizcaya. En conjunto el AMB (gráfico 1) da un porcentaje de empleo en servicios $(73,6 \%)$ más elevado que el del País Vasco $(68,3 \%)$, indicador de un nivel de terciarización más avanzado y que sólo es superado por el municipio de Bilbao (85\%). Estas cifras indican de una forma contundente la primacía económica de la aglomeración metropolitana más relevante en el contexto urbano vasco. Al predominio cuantitativo de la

\footnotetext{
${ }^{2}$ El mayor porcentaje de empleo en EC respecto al total del empleo de cada TH lo alcanza Guipúzcoa, debido a su tradicional especialización en maquinaria, que es uno de los subsectores incluidos en las actividades intensivas en conocimiento (tabla 2), seguido de Vizcaya y Álava.
} 
AMB se une la hegemonía tanto en volumen como en diversificación del sector servicios. En el gráfico 1 podemos observar que en el municipio de Bilbao el predominio de servicios es absoluto ( $85 \%$ del empleo total). A medida que nos distanciamos de la ciudad central hacia la primera corona metropolitana va descendiendo la participación de servicios $(76,7 \%)$, siendo en la segunda corona (53\%) más notable ese descenso y ascendiendo en esa segunda corona el porcentaje de empleo en industria. La posición de liderazgo del tejido económico de la AMB en Vizcaya y en el País Vasco revela, por tanto, la distribución no homogénea en el territorio del empleo en el nivel sectorial clásico (agricultura, industria, construcción, servicios) de desagregación y la preferencia de los servicios por las zonas más accesibles (Bilbao y $1^{\mathrm{a}}$ corona de AMB).

Tabla 5. Estructura del empleo en el Área Metropolitana de Bilbao y la CAPV en 2009.

\begin{tabular}{|l|c|c|c|c|c|}
\cline { 2 - 6 } \multicolumn{1}{c|}{} & Agricultura & Industria & Construcción & Servicios & TOTAL \\
\hline CAPV & 12.855 & 201.222 & 76.879 & 626.104 & 917.060 \\
\hline $\begin{array}{l}\mathrm{AMB}^{3}\left(1^{\mathrm{a}} \mathrm{y}^{\mathrm{a}}\right. \\
\text { corona })\end{array}$ & 2.082 & 72.768 & 37.511 & 313.358 & 425.719 \\
\hline $1^{\mathrm{a}}$ Corona & 1.218 & 51.723 & 33.244 & 283.792 & 369.977 \\
\hline $2^{\mathrm{a}}$ Corona & 864 & 21.045 & 4.267 & 29.566 & 55.742 \\
\hline BILBAO & 604 & 12.180 & 13.212 & 148.856 & 174.852 \\
\hline
\end{tabular}

Fuente: Tesorería General de la Seguridad Social 2009 y elaboración propia.

Gráfico 1. Distribución del empleo por sector (\%) y ámbito espacial en 2009

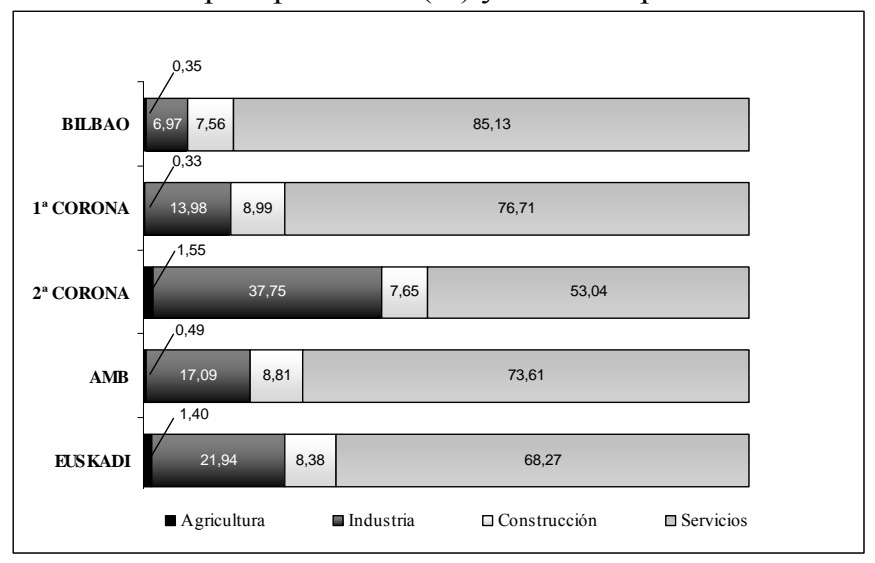

Fuente: Tesorería General de la Seguridad Social 2009 y elaboración propia.

\footnotetext{
${ }^{3}$ AMB Aglomeración Metropolitana de Bilbao. $1^{\text {a }}$ Corona: comarca del Gran Bilbao. $2^{\text {a }}$ Corona: Comarcas de Plentzia-Mungia y Duranguesado
} 
Veamos a continuación la entidad de la EC y su comportamiento espacial en la AMB (tabla 6 y gráfico 2). La EC en la AMB supone la mayor concentración en el País Vasco con el 47,5\% del empleo regional, superando ligeramente a la participación del empleo en todos los sectores $(46,4 \%)$ y en términos relativos también destaca ostentosamente donde la EC alcanza el $29,5 \%$ de su empleo total (gráfico 2). El avance de la EC en el AMB vendría a confirmar el cambio en la estructura productiva hacia actividades basadas en la innovación y el conocimiento con la consiguiente deslocalización de la industria. La hipótesis de la tendencia a la concentración de la EC vendría a reafirmarse al alcanzar el mayor volumen (59.829 empleos) y proporción en Bilbao $(34,2 \%)$, el municipio más céntrico, e ir disminuyendo en la primera $(30,4 \%)$ y segunda corona $(23,9 \%)$ a medida que aumenta la distancia desde la capital. Esta graduación está derivada del mayor porcentaje del empleo de servicios en la primera corona $(76,7 \%)$ y en Bilbao $(85,1 \%)$, correlacionada con la mayor presencia del empleo industrial (37,5\%) en la segunda corona de la AMB. Este tipo de distribución espacial de la EC muestra que sigue vigente la clásica relación entre coste del suelo y accesibilidad (tabla 1). Las actividades que precisan un mayor consumo de suelo, como la industria y la logística, adoptan una localización más periférica donde el precio del suelo tiene un menor coste, aunque la accesibilidad al centro urbano es algo inferior y es mayor a la red principal de carreteras. Por el contrario, los servicios son actividades menos intensivas en el consumo de suelo, pero éste requiere mayor accesibilidad a las áreas de negocios más valoradas y por tanto exige un coste mayor. Las economías de proximidad (las ventajas de la accesibilidad, del intercambio de información, de la concentración de empresas interrelacionadas, acceso a infraestructuras de conocimiento como laboratorios, concentración de agentes con capacidad de decisión, etc.) están muy vinculadas a la EC.

Gráfico 2. Porcentaje de empleo vinculado a la economía del conocimiento en 2009

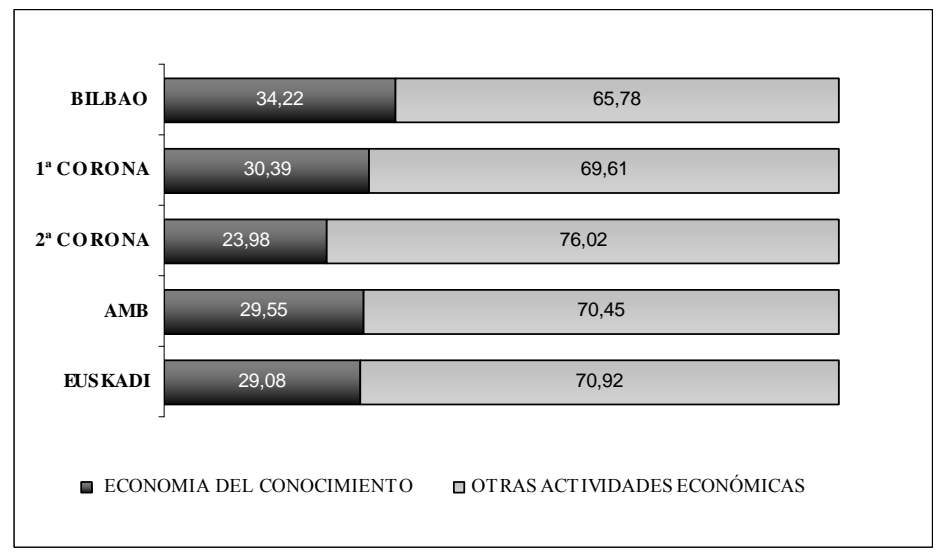

Fuente: Tesorería General de la Seguridad Social 2009 y elaboración propia. 
Tabla 6. Volumen de empresas y afiliados en economía del conocimiento en 2009

\begin{tabular}{|c|c|c|c|c|c|c|c|c|c|}
\hline $\begin{array}{l}\text { Unidades } \\
\text { Territoriales }\end{array}$ & 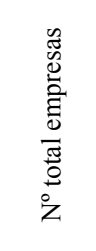 & $\partial^{\circ}$ & 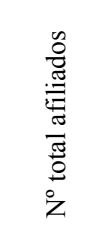 & 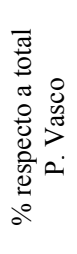 & 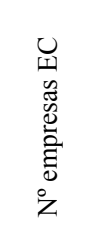 & $0^{\circ}$ & 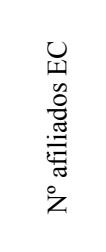 & 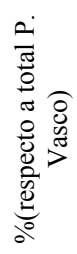 & 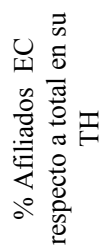 \\
\hline $\begin{array}{c}\text { Ciudad de } \\
\text { Bilbao }\end{array}$ & 16.016 & 19,87 & 174.852 & 19,22 & 3.740 & 26,73 & 59.829 & 22,61 & \\
\hline $\begin{array}{l}\text { Aglomeración } \\
\text { Metropolitana } \\
\text { de Bilbao } \\
\text { (AMB) }\end{array}$ & 36.992 & 45,90 & 425.719 & 46,79 & 7.025 & 50,21 & 125.803 & 47,54 & \\
\hline $\begin{array}{l}1^{\mathrm{a}} \text { Corona de } \\
\mathrm{AMB}\end{array}$ & 32.209 & 39,96 & 369.977 & 40,66 & 6.365 & 45,49 & 112.438 & 42,49 & \\
\hline $\begin{array}{l}2^{\mathrm{a}} \text { Corona de } \\
\mathrm{AMB}\end{array}$ & 4.783 & 5,93 & 55.742 & 6,13 & 660 & 4,72 & 13.365 & 5,05 & \\
\hline Vizcaya & 40.858 & 50,69 & 459.767 & 50,53 & 7.425 & 53,07 & 131.511 & 49,70 & 28,6 \\
\hline Guipúzcoa & 27.454 & 34,06 & 300.007 & 32,97 & 4.516 & 32,28 & 92.955 & 35,13 & 31 \\
\hline Álava & 12.287 & 15,24 & 150.140 & 16,50 & 2.051 & 14,66 & 40.163 & 15,18 & 26,8 \\
\hline $\begin{array}{l}\text { Total País } \\
\text { Vasco }\end{array}$ & 80.599 & 100 & 909.914 & 100 & 13.992 & 100 & 264.629 & 100 & 29,1 \\
\hline
\end{tabular}

Fuente: Tesorería General de la Seguridad Social 2009 y elaboración propia.

La tendencia a la concentración de las actividades intensivas en conocimiento en el AMB es común a lo experimentado en las dos regiones metropolitanas principales, tanto en Madrid (Méndez y Tébar, 2011) como en Barcelona (Muñiz-García, 2009). A nivel interurbano en España esa tendencia a la concentración de la EC en las metrópolis de mayor rango (Madrid y Barcelona) también es constante, evidenciándose la correlación entre mayor tamaño urbano y sectores intensivos en conocimiento, al igual que en otros sistemas urbanos europeos (Méndez y Sánchez Moral, 2011). A continuación ahondaremos en la composición sectorial de la EC en la aglomeración bilbaína, que ilustra la revitalización económica lograda. 


\subsection{EL DESIGUAL SIGNIFICADO DE LA ECONOMÍA DEL CONOCIMIENTO EN LA AMB}

Los subsectores más importantes de la EC en AMB (tabla 7 y 2) teniendo en cuenta el empleo son servicios avanzados a las empresas, educación, sanidad e industrias de alta y media-alta intensidad tecnológica. La participación de cada subsector respecto al total del empleo en la AMB oscila entre un 4,75\% de las industrias de alto y medio-alto contenido tecnológico y un $8,13 \%$ de los servicios avanzados a las empresas. Una mayor desagregación de los datos nos permite observar que en servicios avanzados las actividades más relevantes son servicios de arquitectura e ingeniería, actividades jurídicas y de contabilidad, y en tercer lugar programación, consultoría y otras actividades relacionadas con la informática. En el caso de la educación y la sanidad los datos no ofrecen mayor detalle. En las industrias de alta y media-alta intensidad tecnológica destacan fabricación de maquinaria, material y equipo eléctrico, automoción y aeronáutica. El análisis de los datos estadísticos ha sido optimizado con entrevistas semiestructuradas realizadas a empresas y entidades de la EC en el AMB.

La primera posición conseguida por servicios avanzados a las empresas en la EC del AMB (al igual que en Madrid), es un indicador expresivo de que el tradicional déficit de servicios existente en Vizcaya hasta 1985 ha sido finalmente superado (Alberdi, 2010). El crecimiento de estos servicios sobre todo de 2000 a 2006 en Vizcaya está cifrado en 13.196 empleos (según datos de la Seguridad Social en la categoría "otras actividades empresariales", supuso un crecimiento del 34,47\%). Esta tendencia es recogida igualmente en el País Vasco, donde los servicios a empresas registran el mayor crecimiento porcentual de empleo (26,1\%) de 2000 a 2008 (Orquestra, 2011: 90). La existencia de este subconjunto de actividades terciarias es clave en el tejido productivo metropolitano por su interrelación con otros subsectores de servicios y de industria. Su proyección geográfica más allá de la demanda local y las conexiones establecidas con otras metrópolis nacionales e internacionales suponen un firme cimiento para posicionar a Bilbao en la jerarquía urbana española y europea. La oferta formativa en Bilbao de estudios universitarios en ingeniería, derecho, economía e informática, y de arquitectura en San Sebastián no parece ser una mera coincidencia. Una compleja red de relaciones universidad-empresa-ciudad labradas durante décadas ha sido decisiva en la creación de ventajas comparativas en el cluster del conocimiento universitario bilbaíno. De diferentes promociones de estudiantes han salido dirigentes destacados en el ámbito de la empresa y de las instituciones, no sólo en País Vasco sino también en España y a nivel europeo. La participación en la docencia de profesionales de la empresa ha aportado durante décadas un excepcional valor añadido en las aulas universitarias. En la actualidad la retroalimentación empresa-universidad está sustentada en diferentes canales (prácticas de empresa, contratos de investigación etc.) de los cuales subrayamos las aulas patrocinadas por empresas con capital de origen local de ámbito global, una fórmula para promover la investigación aplicada y la formación avanzada. 
Tabla 7. Distribución del empleo en EC en la Aglomeración Metropolitana de Bilbao (AMB) en 2009

\begin{tabular}{|l|c|c|c|c|}
\hline \multicolumn{1}{|c|}{ ACTIVIDADES EC EN AMB } & Empresas & \% total & Afiliados & $\%$ total \\
\hline Industrias de alta y media-alta intensidad & 736 & 1,99 & 20.206 & 4,75 \\
tecnológica & 546 & 1,48 & 11.591 & 2,72 \\
Finanzas y seguros & 3.159 & 8,54 & 34.592 & 8,13 \\
Servicios avanzados a las empresas & 775 & 2,10 & 26.233 & 6,16 \\
Educación & 1.147 & 3,10 & 25.210 & 5,92 \\
Sanidad & 662 & 1,79 & 7.971 & 1,87 \\
Industrias y servicios culturales & 7.025 & 18,99 & 125.803 & 29,55 \\
\hline Total Economía del Conocimiento AMB & 29.967 & 81,01 & 299.916 & 70,45 \\
\hline Restantes actividades económicas AMB & 36.992 & 100 & 425.719 & 100 \\
\hline TOTAL (EC+REST.ACT.ECON.) AMB & & & \\
\hline
\end{tabular}

Fuente: Tesorería General de la Seguridad Social 2009 y elaboración propia.

Si bien carecemos de datos de la estructura empresarial por tamaño en la EC en AMB podemos apuntar que de las empresas grandes y medianas podemos documentar esa interrelación entre ciudad y actividad económica. No pueden ser en tal sentido más elocuentes las declaraciones del presidente de una empresa multinacional de arquitectura e ingeniería de origen bilbaíno: "Nosotros nacimos en Bilbao hace 55 años, siempre hemos estado comprometidos con esta ciudad y su entorno. (...) Bilbao no es sólo la sede del grupo y la oficina más antigua, también es la más potente, la más numerosa y donde están las raíces de la compañía" (Ayuntamiento de Bilbao, 2012). Asimismo, resulta de interés reseñar el perfil sectorial y por tamaño de las empresas instaladas en la Torre Iberdrola en Abandoibarra (El Correo, 2012). Este espacio de terciario superior representa la oferta de suelo más elitista del AMB y pretende emular a las Cuatro Torres Business Area de Madrid. De hecho algunas de las empresas instaladas requieren una identificación con el paisaje urbano de los nuevos centros de negocios y adoptan una pauta locacional similar en las oficinas de Madrid y Bilbao. Las actividades que reúnen más empleo en la Torre Iberdrola son sedes centrales, consultoría y gestión, junto con auditoría; en un segundo nivel están seguros y finanzas. En lo relativo al tamaño empresarial destacan las empresas por encima de 99 empleos $(75,8 \%$ del empleo total), siendo su origen tanto local como multinacional. El tramo de 50 a 99 empleos está escasamente representado $(5,6 \%$ del empleo total) y el intervalo de 1 a 49 supone $18,6 \%$ del empleo total. El nivel de ocupación de la superficie de oficinas ha ido ascendiendo hasta el 60\% (29/9/2012). Un reflejo de las interrelaciones entre este tipo de empresas y cómo la concentración es la opción de localización preferente en la EC lo constituye esta afirmación del responsable de una multinacional de la auditoría en Bilbao: "para nosotros es importante estar cerca de Iberdrola, que es uno de nuestros grandes clientes" (El Correo, 2012). La Torre Iberdrola situada en el eje de la Ría, es un nuevo símbolo de la ciudad por su alto impacto visual en el paisaje urbano, ya que con sus 41 plantas que 
se alzan a 165 metros constituye el edificio de mayor altura de la ciudad y visible desde innumerables ubicaciones del área metropolitana. Supone la conclusión de las obras de urbanización del ambicioso proyecto de renovación urbana y económica de la metrópoli bilbaína. Representa la localización céntrica de un espacio elitista de oficinas y recupera el proyecto inicial de Abandoibarra como centro de negocios (Esteban, 2005). La Torre Iberdrola, junto a las Torres Isozaki, constituyen los nuevos centros terciarios de Bilbao, pudiendo estar operándose una relocalización centrífuga hacia el eje de la Ría desde el anterior CBD en el Ensanche (calles Gran Vía, Plaza Moyúa y Alameda Recalde). La actuación en Abandoibarra ha sido calificada de urbanismo empresarial y poco creativa (Rodríguez y Vicario, 2005), si bien el coste de no hacer nada en esa zona hubiera sido bastante más perjudicial desde un punto de vista socioeconómico y urbano.

El segundo y tercer puesto en la EC del AMB está ocupado por educación $(6,16 \%$ del empleo total del AMB) y sanidad (5,92\%). Ambos sectores tienen en común la notable participación del sector público por su orientación a satisfacer servicios básicos de la población y la participación del sector privado al tratarse de un área metropolitana con un tamaño que alcanza una masa crítica suficiente. La coexistencia del sector público y privado aporta complementariedades, flexibilidad y ampliación del área geográfica de influencia de ambos servicios.

La educación, con una oferta diversa y sofisticada, es un pilar imprescindible en una economía regional basada en el conocimiento. La UPV/EHU (Universidad del País Vasco) y la UD (Universidad de Deusto) ubicadas en el área metropolitana son las dos instituciones más conocidas, a lo que habría que añadir en los niveles previos numerosos centros de formación en el ámbito privado y público (Navarro y Larrea dir. 2007). La tradicional interrelación entre la docencia universitaria y la investigación ha realzado el papel de la universidad en el ámbito de la generación del conocimiento. En el período actual la competencia en el conocimiento exige realizar investigación de excelencia para integrarse y liderar las redes de ámbito europeo y global (Huggins y Izushi, 2007). Esta globalización del conocimiento ha exigido que la universidad mejore la gestión de la investigación para optimizar resultados (www.ikerkuntza.ehu.es; www.research.deusto.es). El Campus de Vizcaya de la UPV/EHU es un agente activo en investigación por el volumen de fondos gestionados, por grupos de investigación y número de investigadores, con una participación que supera el $50 \%$ del total de la institución. En conjunto, dicho Campus en la última década ha experimentado una evolución positiva en la integración con otros agentes de la Red Vasca de Ciencia, Tecnología e Innovación (RVCTI) y del entorno europeo, ha afianzado las relaciones con el tejido empresarial y ha mejorado la visibilidad internacional de la investigación (De Moya dir., 2010). No obstante, queda un largo recorrido en el reto de transformar el rendimiento del capital intelectual en resultados tangibles, generar sinergias entre grupos de investigación y mejorar la participación de la financiación en convocatorias competitivas. En esa hoja de ruta fue proyectado el Parque Científico de la UPV/EHU (integrado en el Parque Científico y Tecnológico de Bizkaia), ubicado en los solares anejos al Campus de Leioa y emulando al primer parque tecnológico a nivel mundial de la Universidad de Standford, poniendo 
las bases físicas de la proximidad entre la concentración de conocimiento y el tejido empresarial ${ }^{4}$. El Campus Deusto Bilbao de la Universidad de Deusto ha mostrado en investigación una apuesta por la internacionalización, la integración en la RVCTI y la mejora de resultados en la producción científica.

Otro sector reseñable de la EC es la sanidad. En el AMB están localizados los principales hospitales de la red pública (Hospital de Cruces, Hospital de Basurto y Hospital de Galdakao) y privada (IMQ, Quirón ${ }^{5}$ ) de Vizcaya. En torno a la sanidad ha surgido un nuevo subsector: la biomedicina, integrado en el ámbito de las biociencias (nuevo subsector vinculado a la biología, la química, la física, la tecnología médica, la farmacia, la informática, las ciencias de la nutrición y la tecnología medioambiental). El subsector de las biociencias es el prototipo del nuevo tejido empresarial de la EC, al estar apoyado en uso intensivo de personal muy cualificado, infraestructuras muy específicas que requieren inversiones elevadas, nuevo conocimiento que genera nuevos productos y/o servicios y exportación de los mismos. La investigación biomédica es un sector dinámico y competitivo en metrópolis como Houston, Boston y Barcelona. Los institutos de biomedicina en los países más desarrollados han dejado de ser centros de gasto para convertirse en centros de inversión, donde ya se cuantifica de forma positiva y significativa el retorno económico. La producción de nuevos fármacos, biomateriales, implantes y biomarcadores son los nuevos productos y servicios de alto valor añadido, orientados tanto al mercado nacional como al internacional (Princep, 2011).

La política de innovación del Gobierno Vasco en el PCTI (2001-2004) apuesta por las biociencias en el contexto de la segunda transformación económica para convertir al País Vasco en una región líder en conocimiento. La denominada bioregión vasca germina en las capacidades de investigación, manufactura, ingeniería y tecnologías convergentes, pilares imprescindibles de esta nueva economía urbana de las biociencias basada en el conocimiento (www.biobasque.org). Los centros de investigación y tecnológicos vinculados más directamente a la biomedicina en la AMB son: Instituto de Investigaciones Sanitarias BioCruces (IIS BioCruces), Biogune y Achúcarro Basque Center for Neuroscience. IIS BioCruces fue creado en 2011 en el hospital de referencia del País Vasco, Hospital Universitario Cruces (1955). La actividad investigadora es heredera de una larga tradición, ya que fue uno de los primeros hospitales

\footnotetext{
${ }^{4}$ Dicho Parque albergará incubadora de empresas, el edificio de la Fundación Biofísica Bizkaia, el Centro de Biotecnología Animal y el edificio de la Plataforma Tecnológica (www.parque-tecnologico.es)

${ }^{5}$ La sanidad privada tiene una presencia notable en Bilbao. Por una parte, como entidad de mayor tamaño a nivel regional la Clínica IMQ Zorrotzaurre (157 habitaciones), inaugurada en 2012 en el área inmediata a Abandoibarra, simboliza la contribución del IMQ al desarrollo de la revitalización urbana y su firme apuesta por la medicina en el País Vasco. Por otra parte, el grupo Quirón abrió un centro en las proximidades de Abandoibarra (2008) y posteriormente (2010) el Hospital Quirón Vizcaya (110 habitaciones) en Erandio, junto al campus de la UPV/EHU en Leioa, donde está ubicada la Facultad de Medicina. Si bien su trabajo está orientado a la asistencia médica privada y no a la investigación, ambos grupos de sanidad privada son clientes locales potenciales de los nuevos avances en biomedicina.
} 
en España que contaron con unidad de investigación. La misión del IIS BioCruces es trasladar los avances científicos de forma eficaz a la práctica médica asistencial con el objetivo de conseguir una mejora permanente en la salud de las personas. Se trata de organizar la actividad investigadora, que ya se venía realizando en áreas de investigación fundamentales (cáncer, cirugía y biotecnología etc.), áreas de investigación traslacionales (altas tecnologías biomédicas) y áreas de investigación transversal (epidemiología clínica) de modo más coordinado. Esto permitirá obtener sinergias de cara a acelerar la traslación de conocimientos desde la investigación científica básica y la investigación clínica a la resolución de los problemas de salud de la población. BioCruces cuenta con 600 profesionales adscritos (31/9/2012) e integra a personal investigador de diferentes instituciones (hospital, universidad, centros de investigación, socios tecnológicos), si bien el personal perteneciente a Osakidetza-Servicio Vasco de Salud (Gobierno Vasco) es el mayoritario (78\%). BioCruces desarrolla alrededor de 150 ensayos clínicos promovidos por la industria farmacéutica, las sociedades científicas y grupos colaborativos de investigación. Varios ensayos clínicos internacionales son liderados por profesionales de BioCruces por ser referentes mundiales en la materia. La actividad investigadora de dicho instituto está insertada en las redes nacionales e internacionales, siendo reseñable la participación en seis proyectos europeos dotados con 1,4 millones de euros en el período 2008-2012. Por todo ello BioCruces emerge como el mayor instituto de investigaciones científicas en biomedicina en el País Vasco.

En el Parque Científico y Tecnológico de Bizkaia (Zamudio-Derio) en 2005 comenzó su andadura el Centro de Investigación Cooperativa Biogune, dedicado a la investigación en biología estructural, celular y molecular, en 2011 contaba con 132 trabajadores. En dicho Parque otro centro de investigación biomédica es "Achúcarro Basque Center for Neuroscience" (24/10/2012). Dicho centro está orientado a la investigación fundamental (biología del cerebro y sus patologías) y a la traslacional. Integrado en la red B.E.R.C. (Centros de investigación básica y de excelencia), dichos centros surgen de grupos de investigación de referencia internacional de la UPV/EHU e Ikerbasque. El despegue de las biociencias ha estado apuntalado en la labor investigadora no siempre reconocida de muchos médicos, el conocimiento de profesionales que se han hecho emprendedores, la política de apoyo a la empresa y la participación de centros tecnológicos en una región que apuesta por la renovación productiva desde hace décadas. En dicho parque el empleo en empresas de biociencias alcanza el 10\% del total (más de 700 empleos, 31/12/2011). La interrelación entre los grupos de investigación, la UPV/EHU, el tejido empresarial, la industria farmacéutica, los socios tecnológicos, las infraestructuras diferenciadas, el apoyo institucional a la empresa de alto contenido tecnológico y en conocimiento conforman un incipiente cluster en biomedicina en el AMB, que genera ventajas competitivas vinculadas a la concentración y a la interacción. Ha supuesto la diversificación de la estructura productiva, la interrelación entre diferentes sectores, áreas de conocimiento y tecnológicas. En este contexto, y no sólo por el imán del Museo Guggenheim, podemos entender que Bilbao haya conseguido hacerse un hueco como ciudad congresual de diferentes especialidades de medicina, acontecimientos ya habituales en el Palacio de 
Congresos Euskalduna, y que por la repercusión económica en la ciudad son valorados muy positivamente. Bilbao emerge como la capital vasca de la biomedicina por el número de investigadores, de grupos científicos, la producción científica indexada y el volumen de recursos de financiación, así como la participación en organizaciones biomédicas a nivel nacional e internacional, al ser el nodo de una red biomédica en la que también están $\mathrm{S}$. Sebastián, Vitoria y Pamplona ${ }^{6}$. En la región South East del Reino Unido, cuya ciudad más importante es Oxford, ha sido analizado el cluster de la biotecnología y destacan diversos factores territoriales (colaboración entre empresas a nivel local y mundial, personal cualificado, laboratorios privados de investigación en medicina, institutos de investigación de la universidad, investigación clínica aplicada en los hospitales de la región, alto nivel de emprendizaje, accesibilidad a Londres) para entender el éxito de la economía del conocimiento de esta región puntera a nivel mundial (Capello, 2013).

El cuarto lugar en la EC lo ostentan las industrias de intensidad alta y media-alta tecnológica con un 4,75\% del empleo total de AMB. En las industrias de media-alta intensidad tecnológica hay sectores de larga tradición en Vizcaya como maquinaria, material y equipo eléctrico, automoción y química. Sectores que emprendieron hace más de dos décadas un decidido giro a la innovación y a la internacionalización. La adaptación a las mayores condiciones de competencia ha sido asimilada con producto propio ó como proveedores de primer y segundo nivel (tier 1 y 2) de empresas de origen local globalizadas y empresas multinacionales localizadas en el País Vasco. La oferta regional en $\mathrm{I}+\mathrm{D}+\mathrm{i}$ ha sido un sólido apoyo para estas industrias $\mathrm{y}$, en particular, merece ser subrayado la aparición de centros de I+D especializados. Es el caso del Automotive Intelligence Center (A.I.C.) en Amorebieta, Vizcaya, (2009), que surge con el objetivo de mejorar la competitividad del sector de la automoción. Es una fundación respaldada por la Diputación Foral de Bizkaia, los ayuntamientos de Amorebieta y Ermua, un grupo de empresas de vanguardia del sector del automóvil y el Cluster de Automoción del País Vasco. Mediante un modelo de compartir infraestructuras desarrollan actividades de investigación, formación, tecnología y de desarrollos en automoción.

Vinculado a la actividad fabril de última generación está la industria de alta intensidad tecnológica, que agrupa a sectores como la aeronáutica, la fabricación de productos informáticos, electrónicos y ópticos, fabricación de productos farmacéuticos. Por las intensas relaciones entre estos sectores industriales y los servicios avanzados a

\footnotetext{
${ }^{6}$ La denominada bioregión vasca apunta a su consolidación en el medio plazo. En Guipúzcoa está localizado el IIS Biodonostia en San Sebastián (298 investigadores en 2011). Un incipiente tejido empresarial en biociencias está localizado principalmente en el Parque Tecnológico de Miramón, vinculado a la iniciativa de profesionales muy enraizados en la ciudad donostiarra y a dicho centro. En Álava el IIS BioAraba está en fase inicial y también existe alguna iniciativa empresarial de carácter endógeno con proyección internacional.
} 
empresas hemos de subrayar la solidez del tejido productivo metropolitano bilbaíno. $\mathrm{La}$ oferta regional en $\mathrm{I}+\mathrm{D}+\mathrm{i}$ es un apoyo imprescindible para estas industrias. Asimismo, la transferencia de conocimiento entre universidad y empresa ha tenido un eco considerable en este tipo de sectores mediante los contratos de colaboración en $\mathrm{I}+\mathrm{D}$ y asesoramiento. Desde diferentes perspectivas (empresarial, Gobierno Vasco, académica) está cada vez más difundido que una EC con proyección de futuro a medio y largo plazo ha de estar engarzada en un tejido industrial tecnologizado y competitivo. El estudio sobre el cluster de la industria aeronáutica y espacial en el País Vasco (López, Elola, Valdaliso y Aranguren, 2012) pone de manifiesto la capacidad decisiva en el arranque del sector de que coincidieran en el tiempo y en el espacio la disposición de mano de obra cualificada en industria y en ingeniería, la acumulación de conocimiento sectorial en la especialización productiva tradicional (fundición, aleaciones especiales, mecanizado...), la apuesta por el riesgo calculado de empresarios locales con visión de futuro, la implicación del gobierno regional de forma inicial y sostenida en el tiempo, la práctica del difícil binomio entre la cooperación y la competencia.

En quinto lugar están los servicios financieros y seguros, con un 2,72\% del empleo total del AMB. Este sector ha ido experimentando una disminución de su participación en la economía metropolitana por la relocalización de la alta dirección en Madrid de entidades financieras de origen local, la unificación de la Bolsa con el Sistema de Interconexión Bursátil Español y la crisis económica iniciada en 2008, con un fuerte sesgo financiero, también ha traído consecuencias negativas en el empleo del sector. En sentido positivo, habría que comentar la localización de la sede social de Kutxabank (2/1/2012) en Bilbao ${ }^{7}$. El sector financiero no sólo forma parte de la EC, sino que es un gran consumidor de servicios avanzados, por lo que mantener el centro decisional en la capital vizcaína tiene un gran eco en este ámbito metropolitano, a lo que hay que sumar las conexiones financieras con metrópolis europeas.

Finalmente, las industrias y servicios culturales con un 1,87\% del empleo consiguen hacerse un hueco a tener en cuenta. En este subgrupo coexisten actividades preexistentes de cierto raigambre (actividades deportivas, recreativas y de entretenimiento, artes gráficas y reproducción de soportes grabados, edición) que son las predominantes en empleo, con otras actividades (cine, vídeo y TV, actividades de creación, artísticas y espectáculos) más vinculadas a la revolución digital y a la cultura contemporánea. La especialización económica en cultura y comunicación, que defienden algunos autores (Zallo, 2011), como sector estratégico en el desarrollo regional, aprovechando las posibles sinergias originadas por la Capitalidad Cultural de San Sebastián 2016, todavía va a necesitar un fuerte impulso en el medio plazo.

\footnotetext{
${ }^{7}$ Kutxabank es el banco que surgió como consecuencia de la fusión de las cajas de ahorro vascas, BBK (de Vizcaya), Kutxa (de Guipúzcoa) y Vital (de Álava), siendo su participación en el capital de 57\%, $32 \%$ y $11 \%$ respectivamente.
} 
La necesidad de centralidad por parte de las empresas y organismos vinculados a la cultura quedó evidenciado con la relocalización en 2007 de la sede central del grupo de comunicación autonómico EITB desde Iurreta (Duranguesado) a Bilbao junto a una zona de alta concentración de servicios (Campus Tecnológico de la UPV/EHU, Campo de Fútbol San Mamés, Hospital de Basurto, Hacienda de la Diputación Foral de Bizkaia ...) y elevada accesibilidad. La relocalización estuvo motivada por diferentes factores. Frente a la anterior fragmentación funcional y locacional, las sinergias que ofrecía la integración de los diferentes canales de distribución (radio, televisión, Internet) en un mismo establecimiento eran inviables sin proximidad física. Esta reorganización espacial permitía el contacto inmediato entre periodistas, documentalistas y técnicos de las diferentes áreas de emisión, así como compartir infraestructuras tecnológicas de alto coste que exigía la revolución digital. Asimismo, la demanda de una amplia parcela de suelo que permitiera absorber el crecimiento de la entidad no podía postergarse más. Por otra parte, la proximidad a la audiencia (más de $50 \%$ de audiencia en Vizcaya) y a la concentración de información a atender en el ámbito de la política, la economía, la cultura y el ocio en la AMB fue otro factor a tener en cuenta. La accesibilidad del enclave junto a la estación intermodal de San Mamés (parada de metro y Renfe cercanías, estación de autobuses), que permite un medio de transporte sostenible a los trabajadores y visitantes, así como su visibilidad urbana sumaban puntos a favor de la actual localización. Un factor adicional es que la cultura dominante en la actualidad tiene su origen y mercado en la ciudad. La identificación con el paisaje urbano en torno al Guggenheim es la imagen del País Vasco más difundida en las emisiones de noticias de televisión y su proximidad desde la actual ubicación resultaba estratégica. Otro factor relevante es la oferta formativa de la UPV/EHU (Periodismo, Publicidad, Ingenierías) en el Campus de Vizcaya, ya que la proximidad facilita la realización de prácticas y proyectos de fin de grado en la radio y televisión vasca. Finalmente, hemos de recordar cómo Bilbao concentra el mayor número de medios de comunicación (radio, periódicos, televisión) del País Vasco y eso genera una interacción entre mercado de trabajo, publicidad, comunicación y otros servicios, que refuerza las ventajas localizadas en AMB.

La inauguración en 2010 de "Alhóndiga Bilbao" como centro cultural y de ocio municipal ha ampliado la oferta de actos culturales muy diversos (exposiciones, conciertos, conferencias, talleres infantiles, deporte) para la población del Bilbao metropolitano, constituyéndose en un atractivo más de una ciudad vibrante. Tanto el Gobierno Vasco (Plan Innova Creativity, 28/2/2012) como el Ayuntamiento de Bilbao (Plan de apoyo 2011-2013 para el desarrollo de la economía creativa en Bilbao) han impulsado actuaciones de apoyo a las industrias creativas. De momento, la escasa participación de industrias y servicios culturales en la EC pone en entredicho que la cultura haya sido el pilar de la transformación económica de Bilbao. El icono cultural del Museo Guggenheim ha sido un motor imprescindible en la renovación urbana de Bilbao y su internacionalización, así como el posterior logro de ciudad turística y congresual. Los datos sobre el impacto económico de dicho museo en 2012 (estimado en 294,6 millones de euros de PIB y el mantenimiento de 6.324 empleos (Guggen- 
heim Bilbao, 2012) ilustran su relevancia en los subsectores más favorecidos (hostelería, transporte y comercio), pero fue uno de los múltiples proyectos de reestructuración económica y renovación urbana (Esteban, 2005).

\section{EL MAPA DE LA ECONOMÍA DEL CONOCIMIENTO EN LA AGLOMERACIÓN METROPOLITANA DE BILBAO}

La segunda gran transformación económica articulada en torno al conocimiento y la innovación en el tejido productivo ha favorecido a la metrópoli bilbaína por concentrar infraestructuras estratégicas, recursos diferenciadores y entidad del tejido empresarial basado en EC en el País Vasco. La ubicación del principal aeropuerto regional, el número y relevancia de centros tecnológicos, el volumen de empleo, la diversidad de áreas de conocimiento e investigación, el número de centros de las universidades pública y privada (UPV/EHU y UD respectivamente), el museo Guggenheim, el palacio de congresos Euskalduna, el grado de internacionalización de las empresas y la atractividad de la ciudad suponen un conjunto de recursos escasos e interrelacionados de alto valor, imprescindibles para que los distintos subsectores de la EC puedan desarrollar su actividad en un contexto estimulante. La proximidad entre trabajadores cualificados, infraestructuras de $\mathrm{I}+\mathrm{D}+\mathrm{i}$ y amenidades urbanas facilita un entorno incentivador a la producción, intercambio y difusión del conocimiento. En definitiva, las ventajas que surgen de las economías de aglomeración en este ámbito metropolitano son apreciadas por los agentes implicados en la EC. A continuación veremos cómo se ha materializado la EC en el territorio metropolitano por excelencia del País Vasco: AMB. En el mapa 2 podemos observar claramente el comportamiento mayoritario de la EC por la centralidad en el área más accesible de toda la AMB, primera corona metropolitana (Gran Bilbao) que continúa por la segunda corona metropolitana (Duranguesado y Plentzia-Mungia) pero disminuyendo de un modo radical en volumen y presencia territorial. En el resto de Vizcaya la EC destaca un enorme vacío espacial, excepto en las capitales comarcales de Guernica y Bermeo. Bilbao revalida su liderazgo como ciudad principal en torno a la que se articulan las localidades que ya estructuraban el área metropolitana desde hace varias décadas (Baracaldo y Guecho) y a la que se vinculan de modo definitivo los municipios que salen reforzados por la EC (Zamudio y Derio por la ubicación del Parque Tecnológico de Bizkaia, Leioa por la UPV/EHU y Mungia por las empresas de medio-alto contenido tecnológico). 
Mapa 2. Distribución del empleo en EC en la AMB en 2009

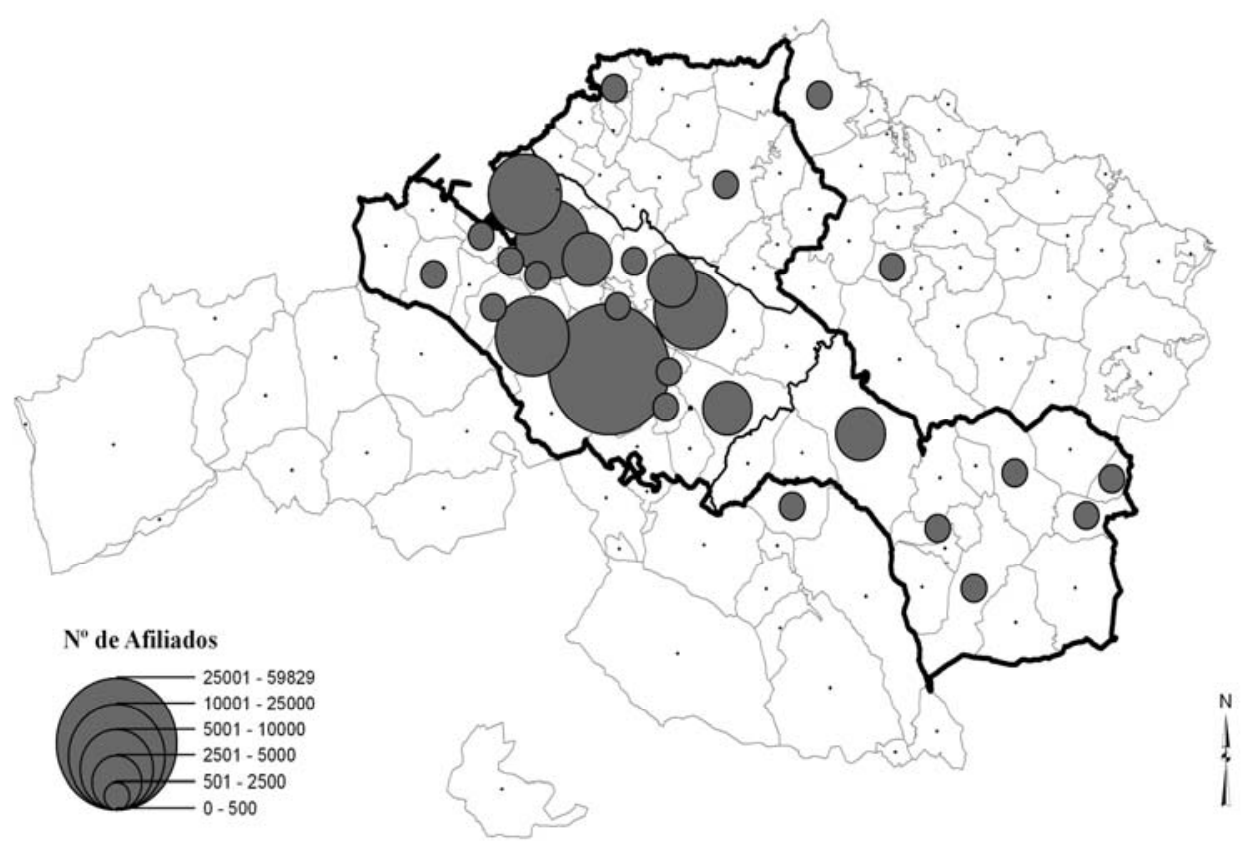

Fuente: Elaboración propia a partir de los datos de la Tesorería General de la Seguridad Social 2009.

La EC radiografía a nivel intrametropolitano una mayor concentración y contigüidad por la margen derecha (Leioa, Getxo) y valle anexo del Txorierri (Zamudio, Derio) frente a la margen izquierda (Baracaldo, Portugalete). La ubicación en Leioa de la UPV/EHU y la oferta de suelo para oficinas en dicho municipio, junto a la imagen urbana de exclusividad paisajística que transmite la vecina localidad de Getxo han jugado a favor de un área que tiene la calidad residencial como marca territorial. Por otra parte, la renovación funcional y urbana operada en la capital de la margen izquierda, Baracaldo, ha surtido efecto con la oferta de suelo en parques empresariales y comerciales. La localización del mayor centro de investigaciones biosanitarias del País Vasco en dicha localidad refuerzan el protagonismo de Baracaldo en el área metropolitana. A la vista de estos resultados podríamos avanzar que nada parece apuntar a que los cambios económicos y metropolitanos hayan impulsado el policentrismo en la AMB, más bien ha habido un reforzamiento de la ciudad central (Bilbao) y de municipios asociados a clusters de conocimiento (Zamudio, Derio, Leioa, Baracaldo). 
El mapa 3 nos revela las pautas locacionales de la EC por subsectores en Vizcaya en 2009. En primer lugar destacaríamos servicios avanzados a empresas y finanzas y seguros (3.b y 3.d respectivamente), que muestran la mayor selectividad espacial, comportamiento similar al registrado en Madrid. Servicios avanzados a empresas está prácticamente ceñido a la primera corona metropolitana. Finanzas y seguros está presente en muy pocos municipios de esa primera corona metropolitana (fuera son municipios poco relevantes). Por el contrario, las industrias de alto y medio-alto contenido tecnológico es la agrupación que manifiesta una presencia territorial más extendida, tanto en la primera corona como en la segunda, revelando la tradición fabril de la metrópoli bilbaína y además los municipios que más destacan de la primera corona son los situados en la periferia de dicha zona. En educación destaca claramente la primera corona metropolitana ${ }^{8}$. En sanidad destaca la notable selectividad espacial y es la primera corona metropolitana la que ejerce el liderazgo, donde los municipios que albergan un hospital o centro sanitario especializado alcanzan los valores más altos. En industrias y servicios culturales destaca la primera corona metropolitana y también hay que mencionar Gernika-Bermeo. Si superponemos los diferentes mapas veríamos cómo la tendencia centrípeta de la primera corona metropolitana es la nota dominante.

Hemos podido comprobar, como señala Foray (2009), que la estrategia de localización de los principales actores de la EC es la concentración. Las externalidades positivas de la aglomeración metropolitana permiten flujos de conocimientos más allá de cada entidad (empresas, institutos de investigación, servicios ...). Por lo que es probable que aumenten los fenómenos de polarización y den como resultado la densificación científica en algunas regiones, la diversificación en otras y la desertificación en las menos afortunadas. Para atenuar este resultado las regiones, y en su caso áreas metropolitanas y ciudades, deben aprender a valorizar sus particularidades en $\mathrm{I}+\mathrm{D}+\mathrm{i}$ mediante estrategias de especialización inteligente que conduzcan a la "smart city".

\footnotetext{
${ }^{8}$ Los municipios fuera de la primera corona (Sopuerta, Ceánuri) aparecen por el escaso volumen de empleo total en dichas localidades del ámbito rural.
} 
Mapa 3. Especialización de AMB según tipos de actividades intensivas en conocimiento (cocientes de localización) en 2009.

3. A. Industrias de alta y media-alta IT

Fuente: Elaboración propia a partir de los datos de la Tesorería General de la Seguridad Social, 2009 


\section{CLAVES EXPLICATIVAS DE LA AGLOMERACIÓN METROPOLITANA DE BILBAO EN RELACIÓN A LA ECONOMÍA DEL CONOCIMIENTO}

En este epígrafe vamos a valorar las claves explicativas que sustentan la EC en la AMB repasando someramente los componentes básicos de las ciudades del conocimiento propuestos por Méndez y Sánchez Moral (2011) (sistema de innovación, estructura económica de la ciudad, resultados tangibles de la innovación, capital humano, conectividad física e inalámbrica) ya comentados en el apartado 1. La pretensión no es un análisis exhaustivo de cada uno de los componentes, sino destacar lo más relevante de cada uno de ellos en el contexto de Bilbao como ciudad del conocimiento.

En relación al sistema de innovación del País Vasco, en el que está integrada la AMB, habría que señalar el ya largo período desde su creación. Las políticas iniciales datan de 1982, la consolidación transcurre en la década de 1990 y la diversificación se remonta al año 2000. Las dos primeras fases están orientadas a la consecución de innovaciones incrementales y a la reducción de costes para las empresas de la región. Desde la década de 2000 el País Vasco está intentando avanzar hacia un sistema de innovación en el que el conocimiento actúe como motor de cambio (OCDE, 2011: 38). Es a partir de 2001 cuando comienza el apoyo a sectores intensivos en conocimiento (bios, nanos, TIC) y energías renovables (Navarro, 2010: 165). El liderazgo locacional del $\mathrm{AMB}$ en la infraestructura de $\mathrm{I}+\mathrm{D}+\mathrm{i}$ está apoyado en la mayor concentración de centros tecnológicos y de investigación del País Vasco. Destaca Corporación Tecnalia (49,1\% del empleo de Tecnalia en el País Vasco está en AMB, a 1/1/2012), primer centro privado de investigación aplicada de España y ocupa el puesto 24 de todos los participantes en el VII Programa Marco de Investigación de la Unión Europea. Su integración en las redes europeas de conocimiento tiene su mejor exponente en el retorno de financiación proveniente de los Programas Marco de Investigación de la UE (86 millones de $€$ en el VII Programa Marco $)^{9}$. Entidades de investigación más recientes, como los Centros de Investigación Cooperativa (CIC) (Biogune en Parque Tecnológico de Bizkaia) y los centros de investigación básica y de excelencia (BC3, BCAM, Unidad de Biofísica y Achúcarro Basque Center for Neuroscience) también están localizados en la AMB. Por otra parte, resulta de interés apuntar el progresivo incremento de interconexión entre los agentes del sistema regional de innovación (centros tecnológicos, empresas, universidades, organismos intermedios), si bien todavía existe margen de mejora. De las doce asociaciones "cluster" (organizadas por pertenencia a sector a nivel regional y lideradas por el Departamento de Industria del Gobierno Vasco) que han jugado un papel estratégico en la formación de redes internas entre diversos agentes (OCDE, 2011: 107) siete están ubicadas en Vizcaya, por lo que la densidad de redes empresariales, tecnológi-

\footnotetext{
${ }^{9}$ La otra gran corporación tecnológica del País Vasco, IK4, está integrada por ocho centros, seis están en Guipúzcoa y dos en Vizcaya.
} 
cas e institucionales tiene una mayor entidad y complejidad en el territorio metropolitano bilbaíno.

En la infraestructura de $\mathrm{I}+\mathrm{D}+\mathrm{i}$ la integración de las instituciones universitarias, públicas y privadas, en el sistema de innovación regional ha ido cobrando una mayor presencia en el País Vasco. Goddard (OCDE, 2007) destaca que de cara a que las regiones sean competitivas en la EC en un entorno globalizado las universidades asumen un papel crucial en sus regiones respectivas por el acceso al conocimiento y el desempeño en la formación de personas, así como por su proximidad a las necesidades del desarrollo local. La existencia desde hace más de un siglo de la universidad aporta a la ciudad una acumulación de conocimiento no improvisable en el corto plazo. Los centros ubicados en Bilbao más relevantes en la conformación de la actual universidad pública, UPV/EHU (1980), fueron la Escuela de Altos Estudios Mercantiles (1818), la Escuela Técnica Superior de Ingenieros Industriales (1897) y la facultad de ciencias económicas y empresariales (1955) (De Pablo y Rubio, 2006). Por su parte, la universidad privada, Universidad de Deusto, fue fundada en 1886 en lo que entonces era la periferia de Bilbao y hoy en día dicha ubicación frente a Abandoibarra conforma uno de los paisajes urbanos únicos y más admirados de la capital vizcaína. Desde una perspectiva contemporánea sobre la presencia de la UPV/EHU en el AMB podríamos subrayar que es en este ámbito geográfico donde está localizado el campus de mayor dimensión, el rectorado y el Paraninfo (Edificio Bizkaia) más emblemático. En el AMB existe la mayor concentración de profesorado e investigadores y estudiantes (58\% y 54,7\% respectivamente del total de UPV/EHU). La UPV/EHU decidió, de común acuerdo con la entidad financiera local (BBK, hoy integrada en Kutxabank) y el Ayuntamiento de Bilbao, ofrecer una mayor visibilidad urbana en la capital vizcaína, materializada en el edificio singular del nuevo paraninfo (Edificio Bizkaia, 2011, ubicado en Abandoibarra junto al Museo Guggenheim) y la operación San Mamés (ampliación del campus tecnológico nucleado en torno a la Escuela Técnica Superior de Ingeniería, municipio de Bilbao). Asimismo hay que reseñar que Bilbao es la sede principal de la Universidad de Deusto (UD), cuya ubicación frente a Abandoibarra y con su nueva Biblioteca-CRAI en dicha zona, realza el mensaje que quieren transmitir las instituciones vascas de Bilbao como ciudad del conocimiento. Ambas universidades han emprendido acciones orientadas a una mayor inserción en las redes europeas de conocimiento, entre las que destacaríamos que la UPV/EHU lidera el proyecto de Campus de Excelencia Internacional "Euskampus" y la UD ha impulsado la internacionalización a través del centro de investigación Orkestra. La Universidad Mondragón, con una oferta docente orientada a la ingeniería y a la gestión empresarial (grupo cooperativo Mondragón Corporación), también ha estimado oportuno la presencia en la metrópoli vasca por excelencia. Se ha materializado con la apertura, mediante un acuerdo con el Ayuntamiento de Bilbao, de "Factoría de Innovación Bilbao" (MU- 
$\mathrm{BBF})^{10}$, cuyo objetivo es ofrecer formación en emprendizaje y asesoramiento en la incubadora de empresas ubicada en la ribera renovada de la Ría. Más allá de la presencia simbólica de las universidades (UPV/EHU, UD y MU) en el paisaje urbano que simboliza el renacimiento de la ciudad, el polo universitario vasco comparte una visión: "globalmente competitivas y localmente comprometidas" (OCDE, 2007). El binomio entre ciudad y universidad tiene su mejor exponente en la especialización en la EC en servicios de arquitectura e ingeniería, servicios jurídicos y auditoría, asociada a la oferta docente de las citadas universidades.

En lo relativo a la estructura económica del área metropolitana aquí quisiéramos destacar la internacionalización de empresas de EC con capital de origen autóctono, que han mantenido la sede social en AMB y la demanda inducida en servicios especializados y genéricos que suscitan. Una investigación reciente (Parrilli coord., 2012) sobre la industria eólica vasca señala que el proceso de internacionalización es una cadena que se transmite desde la empresa globalizada y enraizada localmente al resto de los primeros niveles de los proveedores (tier 1 y tier 2) y socios tecnológicos. Desde el punto de vista de la promoción económica urbana hay que subrayar que estas empresas son auténticas embajadoras de la economía del conocimiento en el exterior y la imagen que transmiten a clientes y proveedores es una aportación incalculable al marketing urbano.

Por otra parte, en relación a los resultados tangibles de la innovación en el ámbito urbano habría que destacar la intensa labor de difusión internacional sobre el proceso de renovación urbana y económica de la ciudad realizada por el Ayuntamiento de Bilbao (en 2012 fueron atendidas 75 delegaciones internacionales). Uno de los logros más significativos fue ser ciudad invitada en la Exposición Universal de Shanghai 2010 y la obtención del Premio "Lee Kuan Yew World City Prize", que otorga la ciudad de Singapur. La promoción urbana ha tenido una larga trayectoria desde la inauguración del Museo Guggenheim (1997) y ha atesorado otros reconocimientos ${ }^{11}$.

En relación al capital humano la valoración de una mano de obra con alto nivel de formación y por tanto una fuerte capacidad de absorción de conocimiento sería lo más representativo (OCDE, 2011: 110) y los datos así lo avalan ${ }^{12}$. Un factor añadido a destacar es la inversión en formación que realizan las empresas en sus trabajadores, que va generando una acumulación de conocimiento en la región metropolitana

\footnotetext{
${ }^{10}$ MU-BBF: Mondragon Unibertsitatea-Bilbao Berrikuntza Faktoria.

${ }^{11}$ Otros reconocimientos: Premio Apex Award al Palacio de Congresos y la Música Euskalduna en 2003, Premio Città d'Acqua en 2004 de la Bienal de Arquitectura de Venecia a Bilbao Ría 2000, Premio Europeo de Planificación Urbana y Regional en 2004 a Bilbao Ría 2000, Premio de excelencia urbanística ISOCARP en 2010 a Bilbao Ría 2000, Premio World City Mayor en 2012 al Alcalde de Bilbao Iñaki Azkuna, Premio a la Intervención en un Espacio Urbano a la Alhóndiga de Bilbao en 2012 por la Asociación Española para la Gerencia de Centros Urbanos.

${ }^{12}$ Utilizando la Clasificación Internacional Normalizada de Educación en 2010 en el nivel 5 (FP de grado superior, titulación universitaria) la $\mathrm{UE}=27$ daba un $17,9 \%$ de estudiantes y en País Vasco era el $16,6 \%$, en el nivel 3 (FP grado medio, educación secundaria obligatoria) la UE=27 da un 20,2\% y País Vasco 17,3\%) (www.eustat.es).
} 
(cifrado en 78,8 millones de $€$ en 2007 en País Vasco). Otra dimensión relativa al capital humano es el objetivo de aumentar el stock de conocimiento que pretenden las estrategias vinculadas al impulso de las ciudades del conocimiento. De cara a inducir la atracción del talento fue creado Ikerbasque (2007) por el Gobierno Vasco, con sede en Bilbao. De los 110 investigadores contratados de 2007 a 2011 el 51\% estuvieron trabajando en centros de investigación ubicados en Vizcaya (Ikerbasque, 2011). Referencia que vuelve a apuntar a la concentración de profesionales vinculados a la $\mathrm{EC}$, a la acumulación de infraestructuras de $\mathrm{I}+\mathrm{D}+\mathrm{i}$ y a un entorno urbano simbólico, Abandoibarra, que representa el paisaje contemporáneo del Bilbao del siglo veintiuno. En un estudio realizado recientemente (Innobasque, 2011) señalan que la localización de empresas y organizaciones que emplean a personas de alta cualificación no residentes en País Vasco ó talento exógeno captado están ubicadas en parques tecnológi$\cos (30,9 \%)$ y entornos urbanos $(22,1 \%)$, una confirmación más de la tendencia de la EC a la polarización como pauta dominante.

Respecto a la conectividad física señalar que el Aeropuerto de Bilbao ofrece conexión a nivel interno en España a los dos nodos de primer rango (Barajas en Madrid y El Prat en Barcelona), desde donde operan vuelos con el resto del mundo, así como a numerosas capitales españolas. Pero lo más característico es su escala europea, con vuelos directos a las principales capitales (Londres, Paris, Frankfurt, Ginebra etc.). Es en esta jerarquía urbana europea en la que Bilbao aspira a mejorar su posicionamiento ${ }^{13}$. En relación a la conectividad aeroportuaria podríamos subrayar la posición estratégica de Bilbao entre Londres, la primera metrópoli europea global (vuelo de 90 minutos) y Madrid, la primera metrópoli española (a 45 minutos). La elevada movilidad del personal empleado en la EC en avión y su localización residencial en dos ciudades (ya sea parte de la semana ó algunas semanas al mes) hacen del aeropuerto una infraestructura metropolitana esencial. Sobre las conexiones por carretera apuntar que pueden calificarse de satisfactorias a pesar de los inevitables puntos negros de densidad de tráfico de cualquier área metropolitana. La deficiencia más acusada estriba en la falta de conexión por medio del tren de alta velocidad (prevista en 2016) y en la actual coyuntura económica de crisis es probable que se retrase. En cuanto al nivel de acceso digital de las empresas podríamos calificarlo de notable ${ }^{14}$. La utilización efectiva de las infraestructuras y servicios de telecomunicaciones en el contexto intraempresarial, interempresarial e institucional es indispensable en el avance de la EC (Tranos-Gillespie, 2011).

Finalmente, sobre los resultados tangibles de la innovación en el ámbito urbano comentaremos que Bilbao está clasificada en la red urbana global (Taylor, 2011;

\footnotetext{
${ }^{13}$ En 2012 ha registrado un tráfico de más de cuatro millones de pasajeros (4.171.092) y operan 12 aerolíneas en vuelos regulares.

${ }^{14}$ En 2011 el nivel de acceso a Internet de las empresas de 10 o más empleados en Vizcaya es del $96,3 \%$ y en la UE=27 de $95 \%$ (www.eustat.es).
} 
Sánchez Moral 2011) en el segundo nivel de metrópolis de la península ibérica, encabezando el ranking Madrid, Barcelona y Lisboa. Nueva York y Londres son las metrópolis globales que ofrecen en el índice de conectividad un 100\%. Bilbao alcanza en dicho índice un 9\% y es una metrópoli regional, al igual que Valencia, Sevilla y Oporto. Madrid obtiene un índice de conectividad del 65\% y Barcelona del $42 \%$. En el estudio POLYNET sobre metrópolis europeas (Hall y Pain, 2005) diferencian cinco categorías de metrópolis. En la cúspide están los nodos globales (Londres, Paris) y luego diferencian la categoría MEGA 1 (Madrid, Barcelona, Milán, Zurich ...), MEGA 2 (Dublín, Manchester, Turín...) y MEGA 3 en la que está incluida Bilbao, junto a otras metrópolis (Valencia, Toulouse, Birmingham, Bologna ...). Este posicionamiento de Billbao, es mejorable pero también satisfactorio si volvemos la vista atrás a la década de 1980 cuando la capital vizcaína estaba inmersa en un proceso de declive económico y urbano.

\section{CONCLUSIONES}

La EC está decantada por la tendencia espacial a la concentración, cualquiera que sea la escala geográfica de comparación (Bilbao respecto a Vizcaya, AMB respecto a País Vasco). Bilbao ejerce una fuerza centrípeta indiscutible en el AMB. La EC ha reforzado a Bilbao, que es el nodo central con capacidad de liderazgo y también a los municipios del AMB destacados en EC (Baracaldo, Leioa, Zamudio y Getxo). Si la escala de análisis sería a nivel nacional e internacional esa tendencia a la concentración también aparecería. Los subsectores en los que destaca la EC están relacionados con la oferta docente de las universidades establecidas en la región (en servicios avanzados despuntan arquitectura, ingeniería, derecho y economía) y con el tejido productivo precedente que se ha constituido en los cimientos para la aparición de nuevos sectores con alto contenido en tecnología, innovación y conocimiento. La EC precisa de un entorno productivo ya que las unidades de $\mathrm{I}+\mathrm{D}+\mathrm{i}$ son insuficientes para apuntalar la economía de una región. En parte, porque sus clientes son las empresas industriales. Por lo que las políticas de reindustrialización serían una opción a tener en cuenta, ya que la bajada de los costes salariales en la UE y su subida en Asia, unido al alza del precio del carburante apuntarían en ese sentido.

La EC es un pilar imprescindible para continuar el proceso de revitalización urbana y económica del AMB. En lo económico por el propio liderazgo de la EC en la jerarquía de actividades económicas y porque aporta competitividad a otros sectores industriales y de servicios. En lo urbano porque proporciona una dimensión más internacional a la metrópoli y subraya el ámbito metropolitano en su región y respecto a su área de influencia. Como señala Hutton $(2007,12)$ "todas las ciudades de la OCDE se verán afectadas por la economía del conocimiento, pero no todas llegarán a ser ciudades del conocimiento". Teniendo en cuenta cómo sitúan al País Vasco (Wintjes y Hollanders, 2010; Fernández-Macho y González Casimiro, 2009) y a Bilbao (Méndez y Sánchez-Moral, 2011; Hall y Pain, 2005; Sánchez Moral, 2011) en diferentes análisis sobre la economía del conocimiento concluimos que en España estaría a un segundo nivel del ranking de la geografía económica del conocimiento y 
a nivel europeo en un cuarto lugar. El AMB dispone de un capital humano, productivo e infraestructural del conocimiento que en el medio plazo facilitará una mejora de la metabolización del conocimiento en el tejido empresarial. Como señala Lagendijk (2011) el reto de superar las tendencias espaciales selectivas de la EC puede ser abordado mediante la integración horizontal (desarrollo económico, innovación, investigación) y vertical (gobernanza multinivel) de las políticas regionales. En este sentido, la ejecución de esa estrategia inteligente será liderada por las metrópolis regionales, como Bilbao, que pueden ejercer un papel de intermediación, de transferencia de conocimiento, entre las metrópolis del conocimiento en la UE de primer rango y los espacios conectados a dichas metrópolis regionales.

El AMB ha demostrado la capacidad para generar ventajas competitivas por la acumulación e interrelación de recursos, infraestructuras, empresas y agentes del conocimiento. En definitiva, la reafirmación del territorio en procesos de generación de innovación y conocimiento queda demostrada. La optimización de determinadas inversiones será mayor en dicha área metropolitana por las sinergias y efectos multiplicadores que pueden generarse en el medio plazo. La crisis económica actual ha demostrado la inviabilidad financiera de un nivel de difusión excesivo en infraestructuras públicas. La capacidad de Bilbao para atraer capital del conocimiento y valorizar el existente, asegurando su sostenibilidad en el medio plazo será clave en la mejora de su posicionamiento en España y la UE.

Finalmente, señalar que este es un trabajo inicial y que posteriores investigaciones a nivel del País Vasco sobre la EC, el talento, la gobernanza del conocimiento y el papel de las ciudades del conocimiento en la ordenación del territorio han de ser abordadas.

\section{BIBLIOGRAFÍA}

ALBERDI, A. (2010). Economía vasca 1980-2010: tres crisis y una gran transformación. Ekonomiaz, 25, 32-95.

ARBONÍES, A.L. y MOSO, M. (2002). Basque Country: the knowledge cluster. Journal of Knowledge Management, 6 (4), 347-355.

AYUNTAMIENTO DE BILBAO (2012). Bilbao. Periódico municipal, 269.

BASTIDA, R. (1923). El problema urbanístico de Bilbao. Reeditado por Basurto, N., Leira, E. y Quero, D. en 1991, Colegio Oficial de Aparejadores y Arquitectos Técnicos de Bizkaia.

BILBAO LAN EKINTZA (2009). Estudio sobre el potencial de las industrias creativas en Bilbao. (http//: www.bilbao.net)

BOSQUE MAUREL, J. y MÉNDEZ, R. edit. (1995). Cambio industrial y desarrollo regional en España. Oikos-tau, Barcelona.

BOIX, R. (2006). Barcelona ciudad del conocimiento: economía del conocimiento, tecnologías de la información y la comunicación y nuevas estrategias urbanas. Ajuntament de Barcelona, Barcelona. 
CAPELLO, R. coord. (2012). KIT. Knowledge, innovation, territory. Final scientific report, volume 2. ESPON \& BEST, Politecnico di Milano.

CASTELLS, M. (1991). The informational city: information technology, economic restructuring and the urban-regional process. Blackwell, Oxford.

COMISIÓN EUROPEA (2010). Europa 2020. Una estrategia para un crecimiento inteligente, sostenible e integrador. Comisión Europea, Bruselas.

COMMITEEE OF DIGITAL AND KNOWLEDGE-BASED CITIES (2012). Smart cities study: international study on the situation of ICT, innovation and knowledge in cities. UCLG.

CLARK, G., HUXLEY, J. y MOUNFORD, D. (2010). Organising local economic development. The role of development agencies and companies. OECD, Paris.

DE PABLO, S. y RUBIO, C. (2006): Eman ta zabal zazu. Historia de la UPV/EHU 1980-2005. Servicio Editorial UPV/EHU.

DE MOYA, F. dir. (2010). La investigación cientifica con visibilidad internacional de la Universidad del País Vasco (Scopus, 2003-2008). Servicio editorial de la Universidad del País Vasco, Bilbao.

El Correo, 22/5/2012.

ESTEBAN, M. (2005). La construcción del nuevo Bilbao. I Jornadas de Campo del Grupo de Geografía Económica-II Encuentro de Geografía Urbana. VitoriaGasteiz.

ESTEBAN, M., UGALDE, M.I., RODRÍGUEZ A. y ALTUZARRA, A. eds. (2008). Territorios inteligentes. Dimensiones y experiencias internacionales. Netbiblo, La Coruña.

ESTEBAN, M. y TORRES, M.C. (2006). La industria en el área metropolitana de Bilbao en Méndez, R y Pascual, H. edit. Industria y ciudad en España. ThomsonCivitas, Navarra.

FERIA TORIBIO, J.M. (2010). La delimitación y organización espacial de las áreas metropolitanas españolas: una perspectiva desde la movilidad residencia-trabajo. Ciudad y Territorio, XLII (164), 189-210

FERNÁNDEZ-MACHO, J. y GONZÁLEZ CASIMIRO, P. (2009). Evaluación de territorios inteligentes en la sociedad del conocimiento. Netbiblo, La Coruña.

FLORIDA, R. (2005). Cities and the creative class. Routledge, Nueva York.

FORAY, D. (2009). L'economie de la connaissance. La Découverte, Paris.

GOBIERNO VASCO y FUNDACIÓN METRÓPOLI (2002). Euskal Hiria. Proyecto Cities Proiektua. Servicio Central de Publicaciones del Gobierno Vasco, VitoriaGasteiz.

GOBIERNO VASCO (2010). Plan de competitividad empresarial 2010-2013. Servicio Central de Publicaciones del Gobierno Vasco, Vitoria-Gasteiz.

GUGGENHEIM BILBAO: (2012). Estudio del impacto económico generado por la actividad del Museo Guggenheim Bilbao 2012.

HALL, P. y PAIN, K. (2005). POLYNET Action 3.1./3.2. Summary report. Institute of Community Studies/The Young Foundation \& Polynet Partners.

HUGGINS, R. y IZUSHI, H. (2007). Competing for knowledge: creating, connecting and growing. Routledge, London. 
HUTTON, W. (2007). Building successful cities in the knowledge economy: the role of "soft policy" instruments. (http://www.theworkfoundation.com)

IKERBASQUE (2011). 5 años 2007-2011 Ikerbasque. (http://www.ikerbasque.net)

INNOBASQUE (2011): La atracción del talento en Euskadi. Factores clave e indicadores. (http://www.innobasque.com)

JUARISTI, J. (2009). La red urbana vasca y el área metropolitana de Bilbao en la transición económica postfordista (1981-2006) en Rodríguez Gutiérrez, F. edit Áreas metropolitanas de España. La nueva forma de la ciudad. Universidad de Oviedo, Asturias.

LAGENDIJK, A. (2011). "Regional innovation policy between Theory and Practice", en Asheim, B.T., Boschma, R., Cooke, P. (Eds.) Handbook of Regional Innovation and Growth. Cheltenham: Edward Elgar.

LÓPEZ, S.M., ELOLA, A., VALDALISO, J.M. y ARANGUREN, M.J. (2012). El cluster de la industria aeronáutica y espacial del País Vasco: orígenes, evolución y trayectoria competitiva. Eusko Ikaskuntza- Orquestra, San Sebastián.

MÉNDEZ, R. (2007). El territorio de las nuevas economías metropolitanas. EURE, 33(100), 51-67.

MÉNDEZ, R. (2000). Procesos de innovación en el territorio: los medios innovadores en Alonso, J.L. y Méndez, R. coord. Innovación, pequeña empresa y desarrollo local en España. Civitas, 23-59, Madrid.

MÉNDEZ, R. edit. (2010). Estrategias de innovación industrial y desarrollo económico en las ciudades intermedias de España. Fundación BBVA, Bilbao.

MÉNDEZ, R. y CARAVACA, I. (1993). Procesos de reestructuración industrial en las aglomeraciones metropolitanas españolas. MOPT, Madrid.

MÉNDEZ, R. y PASCUAL, H. edit. (2006). Industria y ciudad en España: nuevas realidades, nuevos retos. Thomson-Civitas, Navarra.

MÉNDEZ, R. y SÁNCHEZ MORAL, S. (2011). Spanish cities in the knowledge economy: theoretical debates and empirical evidence. European urban and regional studies, 18 (2): 136-155.

MÉNDEZ, R. y TÉBAR, J. (2011). El mapa de la economía del conocimiento en la región metropolitana de Madrid. Anales de Geografia de la Universidad Complutense, Vol. 31, n 2, 139-161.

MEIJERS, E.; HOEKSTRA, J. y AGUADO, R. (2008). Strategic planning for city networks: the emergence of a Basque Global City? Orkestra Working Paper Series in Territorial Competitiveness, 2008-05, 1-32.

MINISTERIO DE VIVIENDA (2007). Atlas estadistico de las áreas urbanas de España 2006. Madrid.

MUNIZ, I, y GARCÍA, M.A. (2009). Policentrismo y sectores intensivos en información y conocimiento. Ciudad y territorio. Estudios Territoriales, XLI (160), 263285.

NAVARRO, M. (2010). Retos para el País Vasco tras tres décadas de desarrollo del sistema y de las políticas de innovación. Ekonomiaz, 25, 136-183. 
NAVARRO, M. y LARREA, M. dir. (2007). Indicadores y análisis de competitividad local en el País Vasco. Servicio central de publicaciones del Gobierno Vasco, Vitoria-Gasteiz.

NAVARRO, M.; ARANGUREN, M.J. y MAGRO, E. (2012). Las estrategias de especialización inteligente: una estrategia territorial para las regiones, Cuadernos de Gestión, Vol. 12, 27-49.

OCDE (2011). Estudios de la OCDE sobre innovación regional: País Vasco, España. OCDE-Innobasque, Bilbao.

OCDE (2007). La educación superior y las regiones. Globalmente competitivas, localmente comprometidas. OCDE, París.

ORQUESTRA (2011). Informe de competitividad del País Vasco 2011. (http://www.orkestra.deusto.es)

PARRILLI, M.D. coord. (2012). Análisis de la cadena de valor de la industria eólica vasca: oportunidades y ámbitos de mejora. Orkestra-Publicaciones de la Universidad de Deusto, Bilbao.

PÉREZ GARCÍA, F. dir. (2012). Crecimiento y competitividad. Motores y frenos de la economía española. Bilbao: Fundación BBVA.

PÉREZ GARCÍA, F.; GOERLICH, F.J. y MAS, M. dir. (1996). Capitalización y crecimiento en España y sus regiones 1955-1995. Fundación BBV, Bilbao.

PRINCEP, M. coord. (2011). Informe biocat 2011. Estado de la biotecnología, la biomedicina y la tecnologías médicas en Cataluña. Retrato de un sector en movimiento. Biocat, Barcelona.

RODRÍGUEZ, A. y VICARIO, L. (2005). Innovación, competitividad y regeneración urbana: los espacios retóricos de la ciudad creativa en el nuevo Bilbao. Ekonomiaz, 58, 262-295.

RUIZ, E. y GALDÓS, R. (2008). Geografia del País Vasco. Nerea, San Sebastián.

SÁNCHEZ MORAL, S. (2011). Iberian cities en Taylor, P.J. edit. Global urban analysis. A survey of cities in globalization. Earthscan, London-Washington.

SÁNCHEZ PÉREZ, J.E. coord. (2009). Barcelona: de ciudad industrial a metrópolis internacional en III Jornadas de Campo de Geografía Económica. GGE/AGE, Barcelona.

SASSEN, S. (1991). The global city: New York, London, Tokyo. Princeton University Press, Princeton, N.J.

SCOTT, A.J. ed. (2002). Global city-regions. Trends, theory, policy. Oxford University Press, Oxford.

TAYLOR, P.J. Edit. (2011). Global urban analysis. A survey of cities in globalization.: Earthscan, London-Washington.

TORRES, M.C. (1995). Industria y territorio en Bizkaia. IVAP, Vitoria-Gasteiz.

TORRES, M.C. (1998). La industria en la Comunidad Autónoma del País Vasco en Meaza, G. y Ruiz, E. dir. Geografia de Euskal Herria. Ostoa, Lasarte-Oria.

TRANOS, E. y Gillespie, A. (2011). The urban geography of Internet backbone networks in Europe: roles and relations. Journal of urban technology, vol. 18, $\mathrm{n}^{\mathrm{o}} 1$, $35-50$.

UD. Memoria de investigación 2010-2011. 
UPV/EHU. La Universidad del País Vasco en cifras 2010/2011. (http://www.ehu.es) UPV/EHU. Informe de gestión. Curso académico 2010/2011. (http://www.ehu.es) VV.AA. (1999). La economía del conocimiento. Ekonomiaz, $\mathrm{n}^{\circ} 45$.

VV.AA. (2011). Industrias culturales y creativas en la sociedad del conocimiento desigual. Ekonomiaz, $\mathrm{n}^{\circ} 78$.

WINTJES, R. y HOLLANDERS, H. (2010). The regional impact of technological change in 2020. ETEPS NET.

YEUNG, H. W.-C. (2009). Regional development and the competitive dynamics of global production networks: an East Asian perspective. Regional Studies, Vol. 43.3, 325-351.

ZALLO, R. (2011). Cultura, industria cultural e innovación en la Comunidad Autónoma de Euskadi: una especialización pendiente, Ekonomiaz, 78, 146-185. 